\title{
Cynandione A alleviates neuropathic pain through spinal microglial interleukin-10/ $\beta$-endorphin expression following a7 nicotinic acetylcholine receptor activation
}

\author{
Qiao-Qiao Han \\ Shanghai Jiao Tong University \\ Min Yin \\ Jiangsu Institute of Botany \\ Zi-Ying Wang \\ Shanghai Jiao Tong University \\ Hao Liu \\ Shanghai Jiao Tong University \\ Jun-Ping Ao
}

Shanghai Jiao Tong University Renji Hospital

Yong-Xiang Wang ( $\square$ yxwang@sjtu.edu.cn )

Shanghai Jiao Tong University https://orcid.org/0000-0001-5557-0076

\section{Research}

Keywords: Cynandione A, neuropathic pain, interleukin (IL)-10, $\beta$-endorphin, a7 nicotinic acetylcholine receptor (a7 nAChR), microglia

Posted Date: July 7th, 2020

DOI: https://doi.org/10.21203/rs.3.rs-40230/v1

License: (c) (i) This work is licensed under a Creative Commons Attribution 4.0 International License. Read Full License 


\section{Abstract \\ Background}

Cynandione A, an acetophenone isolated from Cynanchum Wilfordii Radix, exhibits antihypersensitivity effects in neuropathic pain. This study sought to explore the target molecule and mechanisms underlying cynandione A mechanical antiallodynia, particularly related to the spinal glial expression of IL-10/ $\beta$ endorphin, cAMP/PKA/p38/CREB signaling and a7 nicotinic acetylcholine receptor ( $\alpha 7 \mathrm{nAChR})$ activation.

\section{Methods}

$\mathrm{IL}-10$ and $\beta$-endorphin in the spinal cord of spinal nerve ligation-induced neuropathic pain rats and cultured primary microglia were assessed by qRT-PCR and ELISA assays. Double immunofluorescence staining of IL-10, $\beta$-endorphin with glial and neuronal cellular biomarkers was also conducted in the spinal cord and cultured primary microglia. Microglial phosphorylation of PKA, p38, CREB and STAT3 were detected using western blot.

\section{Results}

Cynandione A significantly attenuated mechanical allodynia in neuropathic rats and substantially increased IL-10 and $\beta$-endorphin (but not dynorphin A) expression in the spinal cords and cultured primary microglia. The IL-10 antibody attenuated cynandione A-induced spinal or microglial gene expression of $\beta$-endorphin and mechanical antiallodynia, whereas the $\beta$-endorphin antiserum blocked cynandione A-induced mechanical antiallodynia but not spinal or microglial IL-10 gene expression. The a7 nAChR antagonist methyllycaconitine significantly declined cynandione A-induced mechanical antiallodynia and spinal or microglial expression of IL-10 and $\beta$-endorphin. Cynandione A stimulated microglial phosphorylation of PKA, p38 and CREB, which was inhibited by methyllycaconitine. Treatment with the adenylyl cyclase inhibitor DDA, PKA inhibitor H-89, p38 inhibitor SB203580 and CREB inhibitor KG501 attenuated cynandione A-induced mechanical antiallodynia and spinal or microglial expression of $\mathrm{IL}-10$ and $\beta$-endorphin. Cynandione A stimulated spinal phosphorylation of the transcription factor STAT3, which was inhibited by methyllycaconitine, $\mathrm{H}-89$ and the IL-10 antibody. The STAT3 inhibitor NSC74859 weakened cynandione A-induced mechanical antiallodynia and spinal expression of $\beta$ endorphin.

\section{Conclusion}

Our results illustrate that cynandione A produces mechanical antiallodynia through spinal microglial expression of IL-10 via the cAMP/PKA/p38/CREB signaling and subsequent $\beta$-endorphin expression via 
the IL-10/STAT3 signaling, following a7 nAChR activation.

\section{Introduction}

As a negative regulator, interleukin (IL)-10 is primarily produced by Th2 cells, activated B cells, monocytes, macrophages and glial cells [1], and regulates pleiotropic effects in inflammation and immunoregulation $[2,3]$. IL-10 exhibits remarkable neuroprotective and antinociceptive effects in the central nervous system [4]. It has been demonstrated that IL-10 inhibited proinflammatory cytokine production, attenuated thermal hyperalgesia induced by chronic sciatic nerve constriction [5] and enhanced morphine analgesia [6]. Local injection of IL-10 eliminated mechanical hyperalgesia caused by carrageenan in hindpaw of rats [7] and its trigeminal ganglia injection decreased trigeminal neuropathic pain induced by infraorbital nerve constriction in rats [8]. Intrathecal injection of IL-10 produced mechanical antiallodynia and thermal antihyperalgesia through spinal microglial expression of $\beta$-endorphin [9]. Furthermore, the spinal glial IL10 and $\beta$-endorphin pathway has been revealed to be associated with the antinociceptive effects of electroacupuncture and the agonists of the glucagon-like peptide-1 (GLP-1) receptor and G proteincoupled receptor 40 (GPR40) in rodent models of neuropathic pain induced by spinal nerve ligation [1012].

Nicotinic acetylcholine receptors (nAChRs), highly expressed in skeletal muscle and the nervous system, are known as pentameric ligand-gated ion channels with a total of 17 subunits ( $\alpha 1-10, \beta 1-4, \gamma, \delta$, and $\varepsilon$ ) identified to date [13]. They are formed from various combinations of the subunits and the homomeric a7 nAChRs is one of the major subtypes found in the mammalian central nervous system [14]. a7 nAChRs are expressed not only in neurons but also in non-neuronal cells such as astrocytes, microglia, oligodendrocyte precursor cells and brain endothelial cells [15-17]. They have attracted more attention recently because their mechanisms of action are involved in neuroinflammation [18], neurodegenerative diseases such as Alzheimer's disease [19] and neuroprotection [20, 21]. Down-regulation of spinal a7 nAChR expression is observed in spared nerve injury- and chronic sciatic nerve constriction-induced neuropathic pain [22]. Furthermore, activation of a7 nAChRs attenuates inflammatory pain, postoperative pain, neuropathic pain and bone cancer pain [23-28]. It was suggested that activation of a7 nAChRs blocked neuropathic pain through promoting expression of the antiinflammatory cytokine IL-10 and inhibiting the expression of proinflammatory cytokines such as IL-1 $\beta, \mathrm{IL}-6$, and TNF- $\alpha[29,30]$. It was also recently revealed that activation of $\mathrm{a} 7 \mathrm{nAChRs}$ produced antinociception in rat models of neuropathic pain and bone cancer pain via spinal microglial pathway of IL-10 and $\beta$-endorphin $[31,32]$.

Cynanchum Wilfordii has long been used in the East Asia countries especially in China, Korea and Japan as a traditional herb medicine for the treatment of insomnia, anxiety, anemia, senescence and various geriatric diseases [33-35]. The acetophenone cynandione A, one of the most active ingredients isolated from Cynanchum Wilfordii, exhibits antiinflammatory activity by protecting mice against endotoxin shock [36]. Cynandione A also attenuated glutamate-induced cytotoxicity and mitigated ischemic injuries in rats with cerebral ischemia [37] and protected cultured cortical neurons from toxicity induced by hydrogen peroxide, L-glutamate and kainate [38]. In addition, intrathecal injection of cynandione A markedly 
stimulated spinal $\beta$-endorphin expression and alleviated mechanical allodynia and thermal hyperalgesia in neuropathic rats. Pretreatment with the microglial activation inhibitor minocycline, the $\beta$-endorphin antibody and $\mu$-opioid receptor antagonist totally attenuated cynandione A-induced mechanical antiallodynia. These results suggest that cynandione $A$ alleviates neuropathic pain through upregulation of spinal microglial expression of $\beta$-endorphin [39]. However, little is known about the target molecule and upstream mechanisms underlying cynandione A-induced $\beta$-endorphin expression and subsequent antinociception, although its antinociception in neuropathic rats was blocked by the a7 nAChR antagonist methyllycaconitine in our preliminary experiment.

In this study, we explored the target molecule and upstream mechanisms underlying cynandione Ainduced spinal microglial IL-10 and $\beta$-endorphin expression and mechanical antiallodynia in neuropathic rats and cultured primary microglial cells. Our results demonstrated that cynandione A produces mechanical antiallodynia in neuropathic pain through spinal microglial IL-10 expression via the cAMP/PKA/p38/CREB signaling and subsequent $\beta$-endorphin expression via the IL-10/STAT3 signaling, following a7 nAChR activation.

\section{Materials And Methods}

\section{Chemicals and reagents}

Cynandione A was extracted, isolated and purified by Institute of Botany, Jiangsu Province and Chinese Academy of Sciences, with $\geq 98 \%$ purity determined by ${ }^{1} \mathrm{H}$-NMR and HPLC. The rabbit $\beta$-endorphin antiserum and recombinant rat IL-10 antibody were purchased from Abcam (Cambridge, UK) and R\&D systems (Minneapolis, USA), respectively. The adenylate cyclase inhibitor 2,5-dideoxyadenosine (DDA) and the PKA activation inhibitor H-89 were obtained from Santa Cruz Biotechnologies (Santa Cruz, Canada), while the p38 activation inhibitor SB203580, CREB activation inhibitor KG501 and STAT3 activation inhibitor NSC74859 were purchased from Selleck Chemicals (Houston, TX, USA), Sigma-Aldrich (St. Louis, MO, USA) and Medchem Express (Boston, USA), respectively. The a7 nAChR antagonist methyllycaconitine citrate was purchased from APEx BIO (Houston, USA). Cynandione A was dissolved in $10 \%$ dimethyl sulfoxide (DMSO) and $20 \%$ polyethylene glycol (PEG400) in $0.9 \%$ normal saline for intrathecal injection and dissolved in $0.1 \%$ DMSO for cell culture. All other drugs or reagents were dissolved or diluted in normal saline.

\section{Animals}

Male adult (160-180 g body weight) and 1-day-old (sex unidentified) neonatal Wistar rats were obtained from the Shanghai Experimental Animal Institute for Biological Sciences (Shanghai, China). The adult animals were housed (3-4 per cage) in the Shanghai Jiao Tong University Experimental Animal Center (Shanghai, China) in room temperature $\left(22 \pm 2^{\circ} \mathrm{C}\right)$ under light conditions of a $12 / 12 \mathrm{~h}$ reversed light-dark cycle (7:00 a.m.-7:00 p.m.). They received food and water ad libitum, accustomed to the laboratory 
environment for 3-4 days before surgery. The research protocols were approved by the Animal Care and Welfare Committee of Shanghai Jiao Tong University and carried out in accordance with the animal care guidelines of the US National Institutes of Health.

\section{Primary cultures of microglia}

Primary microglial cells were isolated from the spinal cords of 1-day-old neonatal rats as previous [11]. The isolated spinal cords were minced and incubated in $0.05 \%$ trypsin in the incubator for 7 minutes. The digestion was terminated using the DMEM supplemented with $10 \%(\mathrm{v} / \mathrm{v})$ fetal bovine serum (FBS), penicillin $(100 \mathrm{U} / \mathrm{mL})$ and streptomycin $(100 \mathrm{mg} / \mathrm{mL})$. The glia cells were then plated into $75-\mathrm{cm}^{2}$ tissue culture flasks ( $1 \times 10^{7}$ cells/flask) that were precoated with poly-L-lysine $(100 \mathrm{mg} / \mathrm{mL})$ and cultured at $37^{\circ} \mathrm{C}$ in a $5 \%$ carbon dioxide incubator. After 8 days of culture, microglial cells were prepared as floating cell suspensions by shaking the flasks at $260 \mathrm{rpm}$ for 2 hours. Unattached microglial cells were removed by washing with serum-free DMEM and centrifuged with $300 \mathrm{~g}$ for 15 minutes, and transferred into new 12- or 24-well plates for further study.

\section{RNA isolation and quantitative reverse transcriptase-polymerase chain reaction (qRT-PCR)}

The spinal lumbar enlargements (L3-L5) were isolated from neuropathic rats and homogenized (4,000 rpm) in the Trizol reagent (Invitrogen, Carlsbad, USA) for 15 seconds with a homogenizer (Fluko Equipment Co, Shanghai, China). The total RNAs from spinal homogenates and primary microglia were extracted using the Trizol buffer and reversely transcribed into cDNA using the ReverTra Ace qRT-PCR RTkit (Toyobo Co., Osaka, Japan) according to the manufacturers' protocols. The qRT-PCR amplification was conducted in a Mastercyclerep realplex (Eppendorf, Germany) using the Realmaster Mix (SYBR Green I; Toyobo Co., Osaka, Japan). The primers used were as follows 5'-GGCTCAGCACTGCTATGTTGCC3' and 5'-AGCATGTGGGTCTGGCTGACTG-3' (IL-10; NM_012854.2; [10], 5'-CCTATCGGGTGGAGCACTTC-3' and 5'-TGGCTCTTCTCGGAGGTCAT-3' (POMC exon 2-3) [40,41], 5'-ACTGCCTGTCCTTGTGTTCC-3' and 5'CCAAAGCAACCTCATTCTCC-3' for the dynorphin A precursor prodynorphin (PDYN) [42], 5'CCAAGGTCATCCATGACGAC-3' and 5'-TCCACAGTCTTCTGAGTGGC-3' (GAPDH) [43]. qRT-PCR was first identified to be specific using the melting curves and the relative expression of each mRNA level was calculated with the $2^{-\Delta \Delta C T}$ method after normalizing $\mathrm{Ct}$ (cycle threshold) values with GAPDH Ct.

\section{Western blot}

Protein supernatants, mechanically homogenized from the spinal lumbar enlargements (L3-L5) and cultured microglia, were lysed in the RIPA lysis buffer which contained 1\% protease inhibitor PMSF and $1 \%$ phosphorylase inhibitors cocktail A/B (Biotool, Houston, USA). The protein solution was denatured at 
$100^{\circ} \mathrm{C}$ after adding $5 \mathrm{x}$ of the SDS protein loading buffer and separated in $10 \%$ of the sodium dodecyl sulfate--polyacrylamide gel electrophoresis (SDS-PAGE) with the PAGE gel electrophoresis and then transferred to a polyvinylidene fluoride membrane using the electrophoretic method. The membrane was then blocked in 5\% skim milk powder dissolved in $1 \times$ TBS containing $0.1 \%$ Tween 20 (TBS-T). After blocking for 1 hour, the membrane was incubated with the primary antibody against p-STAT3 (phosphorStat3, Ser727) (1:1000; Cell Signaling Technology, Danvers, MA, USA), p-PKA (1:2000; Abcam, Cambridge, UK), p-p38 (1:1000; Cell Signaling Technology), p-CREB (1:1000; Cell Signaling Technology), and GAPDH (1:5000; Protein Tech Group, Chicago, USA) overnight at $4{ }^{\circ} \mathrm{C}$ with gently shaking. After collecting the primary antibody and washing the membrane four times with TBS-T (10 minutes once) for the second day, the membrane was incubated with the corresponding second antibody diluted in $5 \%$ skim milk powder dissolved in 1x TBS-T (1:10000), including the goat anti-rabbit IgG (IRDye 800-conjugated, Cell

Signaling Technology) and goat anti-rat IgG (IRDye 700-conjugated, Cell Signaling Technology) for 1 hour at $37^{\circ} \mathrm{C}$ with gently shaking. The second antibody was collected and the membrane was washed with $5 \%$ skim milk powder dissolved in 1x TBS-T for 4 times (10 minutes once). The Odyssey Infrared Imaging system (Li-Cor Biosciences, Lincoln, NE, USA) was used to detect the protein bands, which was analyzed and quantified by using the Image J program (National Institutes of Health, Bethesda, MD, USA). The relative expression of each target protein was obtained after normalization to the GAPDH level as previously reported. The experiments were repeated at least three times.

\section{Immunofluorescence staining}

Double immunofluorescence labeling of IL-10 and $\beta$-endorphin with cellular biomarkers of microglia, astrocytes and neurons was performed in the spinal cord and visualized under a TCS SP8 confocal microscope (Leica Microsystems, Wetzlar, Germany) as described previously [44]. Pentobarbitalanesthetized rats $(40 \mathrm{mg} / \mathrm{kg}$ ) were subjected to the intracardial perfusion with $100 \mathrm{~mL}$ of normal saline to flush blood of the whole body, followed by $60 \mathrm{~mL}$ of $4 \%$ paraformaldehyde $(\mathrm{w} / \mathrm{v})$ to fix cells in the spinal cord. The rats were sacrificed and the spinal lumbar enlargements (L3-L5) were isolated and fixed in $4 \%$ buffered paraformaldehyde for 18 hours and dehydrated in gradient sucrose solutions (10-30\%) at $4^{\circ} \mathrm{C}$. Tissues were entrapped and frozen in the OCT-freeze tissue medium (Leica Microsystems) and cut into $30-\mu \mathrm{m}$ sections. The frozen sections were blocked by $10 \%$ goat serum $(\mathrm{v} / \mathrm{v})$ and $0.5 \% \mathrm{X}-100(\mathrm{v} / \mathrm{v})$ in phosphate-buffered saline (PBS) at room temperature for 1 hour after washing in PBS and baking in a $37^{\circ} \mathrm{C}$-dryer machine for 30 minutes to prevent tissue detachment. The sections were then incubated with the IL-10 antibody (1:100; goat polyclonal; R\&D Systems) or $\beta$-endorphin antiserum (1:100; rabbit polyclonal; Phoenix Pharmaceuticals) with the primary antibodies against cellular biomarkers at $4^{\circ} \mathrm{C}$ for 24 hours. The cellular biomarker antibodies included Iba-1 for microglia (1:100; mouse monoclonal; Millipore, USA), GFAP for astrocytes (1:100; mouse polyclonal; Millipore), and NeuN for neurons (1:60; mouse polyclonal; Millipore). The IL-10 or $\beta$-endorphin staining was visualized with the Alexa Fluor-555conjugated donkey anti-goat secondary antibody (1:200; Invitrogen, California, USA) or Alexa Fluor-555- 
conjugated goat anti-rabbit secondary antibody (1:200; Invitrogen), while the Alexa Fluor-488-conjugated goat anti-mouse secondary antibody (1:200; Invitrogen) was used to detect the cell biomarkers.

For quantification of the intensity of IL-10-, $\beta$-endorphin-, Iba-1-, GFAP- and NeuN-positive cells, photomicrographs of the medial three-fourths of the dorsal horn (laminas I-III) and cultured microglial cells (see below) were taken under a confocal microscope with $\times 10$ or $\times 30$ magnification. An investigator blinded to the experimental groups measured the positively-stained surface area using the computerassisted image analysis program, Image $\mathrm{J}$ software (National Institutes of Health, USA). The background fluorescence was excluded and only immunofluorescence intensity measurements from positive-staining areas were included by low- and high-threshold setup. For the colocalization analysis, the colocalization finder of the Image $\mathrm{J}$ software was used to generate merged images in which colocalized pixels appeared as white.

For the staining and quantification, the cultured primary microglial cells were seeded on the poly L-lysinecoated round coverslips which were placed in the 24-well plates $\left(1 \times 10^{4} /\right.$ well) and cultured overnight. The cells were then washed with PBS 2 hours after cynandione A treatment and fixed in $4 \%$ paraformaldehyde for at least 1 hour, then the coverslips moved in the 12-well plates were incubated in $10 \%$ goat serum $(\mathrm{v} / \mathrm{v})$ and $0.5 \% \mathrm{X}-100(\mathrm{v} / \mathrm{v})$ in PBS for blocking in room temperature for 1 hour. The rest procedures followed the above protocol of the frozen spinal sections except that cultured microglial cells were also stained with the nucleic dye reagent 2-(4-amidinophenyl)-6-indolecarbamidine dihydrochloride (DAPI, 0.1 $\mu \mathrm{g} / \mathrm{mL}$; Beyotime Biotechnology, Shanghai, China) for 3 minutes.

\section{IL-10/ß-endorphin measurements}

The contralateral and ipsilateral spinal lumbar enlargements (L3-L5) were isolated from neuropathic rats 1 hour after intrathecal drug injection and homogenized at $4000 \mathrm{rpm}$ for 15 seconds with a homogenizer (Fluko Equipment, Germany) in $10 \mathrm{mM}$ Tris- $\mathrm{HCl}\left(5 \mathrm{~mL} / 1 \mathrm{~g}\right.$ of tissue) and centrifuged at $4000 \mathrm{rpm}$ at $4^{\circ} \mathrm{C}$ for 15 minutes. In addition, cultured primary microglial cells were placed in 24-well plates $\left(1 \times 10^{5}\right.$ cells/well) and washed once with $1 \mathrm{~mL} /$ well of warm PBS, twice with $1 \mathrm{~mL} /$ well of warm DMEM containing $2 \mathrm{mg} / \mathrm{mL}$ BSA and $15 \mathrm{mmol} / \mathrm{L} N$-(2-hydroxyethyl) piperazine-N-2-ethanesulfonic acid and then incubated with $100 \mu \mathrm{M}$ cynandione A for 2 hours according to the previous study [39]. The cell culture supernatant was collected and further centrifuged at $5000 \mathrm{rpm}$ for 10 minutes at $4^{\circ} \mathrm{C}$, and then aspirated to a new tube. The total protein concentrations in the spinal cord homogenates were measured using the standard bicinchoninic acid protein assay (Beyotime Biotechnology, Shanghai, China). The levels of IL-10 (eBioscience, California, USA) and $\beta$-endorphin (Phoenix Pharmaceuticals, USA) were measured using the commercial fluorescent immunoassay kits. A microplate reader (Multiskan MK3; Thermo Labsystems, Vantaa, Finland) and a fluorescence microplate reader (Thermo Labsystems, Grand Rapids, Wood Ohio, USA) were used to measure the relative fluorescence values and the concentrations of IL- $10 / \beta$-endorphin 
were calculated by a calibration curve performed at the same time. The assays were validated with the linear range of $1-500$ and $1-100 \mathrm{pg} / \mathrm{mL}$ for the $\mathrm{IL}-10$ and $\beta$-endorphin, respectively.

\section{Rat models of neuropathic pain and intrathecal catheterization}

Intrathecal catheterization was performed in rats according to the previously described protocol [45]. Briefly, a 20-cm catheter (PE-10: $0.28 \mathrm{~mm}$ inner diameter and $0.61 \mathrm{~mm}$ outer diameter, AniLab Software \& Instruments Co., Ningbo, China) was inserted into the lumbar level of the spinal cord under inhaled isoflurane anesthesia. The other end of the PE-10 catheter was inserted subcutaneously to the neck and fixed. The spinal nerve ligation procedure was performed at the same time just after intrathecal catheterization. The left L5 and L6 spinal nerves were carefully isolated and tightly ligated with 6-0 silk sutures. The lumbar fascia and skin were sewed by a 4-0 resorbable polyglactin suture after nerve ligation. The rat returned to its single home cage after surgeries for recovery. Only rats with no major motor impairments and significant unilateral allodynia to mechanical stimulation (hindpaw withdrawal thresholds in the operated side $<8 \mathrm{~g}$ ), and with both hindpaws of immediately limp and feeble after intrathecal injection of $10 \mu \mathrm{L}$ of $4 \%$ lidocaine followed by $15 \mu \mathrm{L}$ saline flush were chosen for subsequent experiments. The total of 334 neuropathic rats underwent different drug tests during 1-2 weeks after spinal nerve ligation.

\section{Mechanical allodynia assessment}

The hindpaw withdrawal threshold to mechanical stimuli was measured using a 2290CE electrical von Frey hair (IITC Life Science Inc., CA, USA) according to the previous study [46]. Neuropathic rats were acclimatized to the Plexiglas box on a metal grid for at least 30 minutes. An examiner blinded to the treatment groups performed the behavior testing using a 2290 CE electrical von Frey hair (IITC Life Science, Woodland Hill, CA, USA). The withdrawal thresholds were evoked in both contralateral and ipsilateral hindpaws using the von Frey hair while the rat stood on a metal grid. The increments of force were applied to stimulate the footpad until the rat suddenly withdrew its hindpaw. The lowest force evoking a withdrawal response was considered the threshold, which was averaged from triplicate measurements at a 1-min interval.

\section{Data statistical analysis}

Data were exhibited as means \pm SEM. Two-tailed and unpaired Student t-test, and one-way or repeated measures two-way ANOVA were applied to generate statistical significance values. The post-hoc Student-

Newman-Keuls test was used when the effect of the drug (dose) (for one-way ANOVA, the factor was drug [dose]; for two-way ANOVA, the factors were drug [dose], time, and their interaction) was statistically 
significant. The statistical analysis was performed using GraphPad Prism (Version 7.0, GraphPad Software, San Diego, CA, USA). Probability values were considered statistically significant at $5 \%$ level.

\section{Results}

\section{Cynandione A produced mechanical antiallodynia in neuropathic pain and specifically stimulated spinal microglial expression of IL-10 and $\beta$-endorphin}

We have previously demonstrated that intrathecal injection of cynandione A dose-dependently attenuated mechanical allodynia and thermal hyperalgesia in neuropathic pain, with $E_{\max }$ values of $57 \%$ and $59 \%$ maximum possible effect (MPE) and $\mathrm{ED}_{50}$ values of 14.9 and $6.5 \mu \mathrm{g}$, respectively [39]. In this stduy, we first confirmed its spinal mechanical antiallodynic effect at $100 \mu \mathrm{g}$, an approximately $\mathrm{ED}_{90}$ of cynandione A. Two groups of spinal nerve ligated neuropathic rats ( $n=6$ per group) received single intrathecal injection of $10 \mu \mathrm{L}$ of the vehicle (10\% DMSO and $20 \%$ PEG400 in saline) or $100 \mu \mathrm{g}$ of cynandione $\mathrm{A}$. The withdrawal thresholds in both contralateral and ipsilateral hindpaws of the vehicle-treated control rats were unchanged during the 4 hours of observation. Intrathecal injection of cynandione A did not significantly alter withdrawal thresholds in the contralateral hindpaws, but time-dependently inhibited mechanical allodynia in the ipsilateral hindpaws with the peak effect at 1 hour by $48 \%$ MPE and duration of approximately 4 hours after injection $(P<0.05$, by repeated measures two-way ANOVA followed by the post-hoc Student-Newman-Keuls test; Fig. 1A).

Additional two groups neuropathic rats ( $n=6$ per group) that received the same intrathecal treatments as above were sacrificed 1 hour after injection (peak time of the antiallodynic effect). The spinal cords were collected and homogenized to detect the gene and protein expression of IL-10, $\beta$-endorphin and dynorphin A by using qRT-PCR and immunoassay kits, respectively. As shown in Fig. 1B-1D, intrathecal injection of cynandione $A(100 \mu \mathrm{g})$ specifically stimulated spinal mRNA expression of $\mathrm{IL}-10$ and $\mathrm{POMC}(\mathrm{P}<0.05$, by unpaired and two-tailed Student t-test) but not PDYN. Moreover, intrathecal cynandione A also significantly stimulated spinal protein expression of IL-10 and $\beta$-endorphin $(P<0.05$, by unpaired and twotailed Student t-test; Fig. 1E, 1F).

To further confirm the specific spinal microglial expression of IL-10 and $\beta$-endorphin, their double immunofluorescence labeling was performed with cellular biomarkers of microglia (Iba-1), astrocytes (GFAP) or neurons. Two groups of neuropathic rats ( $n=5$ per group) received intrathecal injection of 10 $\mu \mathrm{L}$ of the vehicle or $100 \mu \mathrm{g}$ of cynandione $A$. The rats were sacrificed 1 hour after injection and the spinal cords were collected for immunostaining. There was no significant difference of the double IL-10/lba-1 immunostaining between contralateral and ipsilateral spinal dorsal horns observed under $\times 10$ or $\times 30$ magnifications. Cynandione A treatment significantly enhanced the double IL-10/lba- 1 immunostaining in both contralateral and ipsilateral spinal dorsal horns compared to the vehicle control (Fig. 2A-2F). In contrast, intrathecal cynandione A injection did not enhance the double IL-10/GFAP immunostaining (2G$2 \mathrm{~L}$ ) or IL-10/NeuN immunostaining (2M-2R). Quantitatively using confocal microscope with $\times 30$ magnification, cynandione A in the contralateral and ipsilateral dorsal horn I-III laminate significantly 
increased the double immunofluorescence intensity of IL-10/Iba- 1 by 8.8 -fold and 9.5 -fold, respectively ( $p$ $<0.05$, by one-way ANOVA followed by the post-hoc Student-Newman-Keuls test; Fig. 2S), but not the double immunofluorescence intensity of IL-10/GFAP (Fig. 2T) or IL-10/NeuN (Fig. 2U).

Furthermore, the specific stimulatory effect of intrathecal cynandione $A$ on $\beta$-endorphin expression was also demonstrated in microglia but not astrocytes or neurons in the spinal dorsal horn (Fig. 3A-3R). Quantitative measurement indicated that cynandione A increased the double immunofluorescence intensity of $\beta$-endorphin/Iba- 1 in the contralateral and ipsilateral dorsal horn I-III laminate by 9.3 -fold and 10.2-fold, respectively ( $p<0.05$. by one-way ANOVA followed by the post-hoc Student-Newman-Keuls test; Fig. 3S), but not the double immunofluorescence intensity of $\beta$-endorphin/GFAP (Fig. 3T) or $\beta$ endorphin/NeuN (Fig. 3U).

\section{Cynandione A stimulated IL-10 and $\beta$-endorphin expression in primary spinal microglia}

We have previously demonstrated that treatment with cynandione $A(3,10,30,100$ and $300 \mu \mathrm{M})$ concentration-dependently stimulated $\mathrm{POMC}$ and $\beta$-endorphin expression in cultured primary microglia (but not astrocytes or neurons), with $\mathrm{EC}_{50}$ values of 38.8 and $20.0 \mu \mathrm{M}$, respectively [39]. In this study we first test its stimulatory effects on IL-10 and $\beta$-endorphin at $100 \mu \mathrm{M}$, an approximately $\mathrm{EC}_{80}$ of cynandione $A$, in cultured primary microglial cells originated from neonatal rats. As previously reported [9], the cultured cells were collected two hours later and digested to detect the gene expression of IL-10, $\beta$ endorphin and dynorphin A by using qRT-PCR, while the cell culture medium was collected to detect the protein expression of IL-10 and $\beta$-endorphin by using commercial fluorescent immunoassays. As shown, treatment with cynandione $A$ in microglia significantly upregulated the mRNA expression of IL-10 and POMC ( $P<0.05$, by two-tailed and unpaired Student t-test; Fig. 4A, 4B), but not PDYN (Fig. 4C). In addition, cynandione $A$ treatment upregulated the IL-10 and $\beta$-endorphin levels in the cell culture medium $(P<0.05$, by two-tailed and unpaired Student t-test; Fig. 4D, 4E).

The stimulatory effect of cynandione $A$ on IL-10 and $\beta$-endorphin was further assessed in cultured primary microglia by using single and double immunofluorescence labeling of IL-10 or $\beta$-endorphin with Iba-1 and the nuclear staining reagent DAPI. Compared with the vehicle control, treatment with cynandione $A(100 \mu \mathrm{M})$ significantly enhanced the IL-10 expression reflected in single or double immunostaining under $\times 30$ magnifications (Fig. $5 \mathrm{~A}-5 \mathrm{H}$ ). Quantitatively, cynandione A treatment significantly increased the double immunofluorescence intensity of IL- $10 / \mathrm{lba}-1$ by 8.99 -fold $(p<0.05$, by one-way ANOVA followed by the post-hoc Student-Newman-Keuls test; Fig. 5I).

In addition, cynandione $\mathrm{A}(100 \mu \mathrm{M})$ treatment also significantly stimulated the $\beta$-endorphin expression in both single and double immunostaining (Fig. 5J-5Q). Quantitative measurement revealed that cynandione A significantly increased the double immunofluorescence intensity of $\beta$-endorphin/lba- 1 by 9.02-fold ( $p<0.05$, by one-way ANOVA followed by the post-hoc Student-Newman-Keuls test; Fig. 5R).

Cynandione A produced mechanical antiallodynia in neuropathic pain through spinal microglial IL-10 expression and subsequent $\beta$-endorphin expression

Page 10/38 
We further explored the causal relationship between spinal microglial expression of IL-10/ $\beta$-endorphin and mechanical antiallodynia in neuropathic pain. Four groups of neuropathic rats $(n=6$ per group) received intrathecal injection of saline $(10 \mu \mathrm{L})$, the IL-10 neutralizing antibody $(2 \mu \mathrm{g})$ or $\beta$-endorphin antiserum (1:10) followed by intrathecal injection of the vehicle $(10 \mu \mathrm{L})$ or cynandione $A(100 \mu \mathrm{g}) 30$ minutes later. The withdrawal thresholds in the contralateral and ipsilateral hindpaws were measured 1 hour after injection. Intrathecal injection of cynandione A inhibited mechanical allodynia in the ipsilateral hindpaws, which was nearly completely blocked by the pretreatment with intrathecal injection of the IL-10 antibody or $\beta$-endorphin antiserum $(P<0.05$, by one-way ANOVA followed by the post-hoc StudentNewman-Keuls test; Fig. 6A). Pretreatment with intrathecal injection of the IL-10 antibody or $\beta$-endorphin antiserum did not significantly affect the baseline mechanical thresholds in the ipsilateral hindpaws as previously reported $[10,39]$.

The above four groups of neuropathic rats were sacrificed immediately after the completion of the behavior testing and the spinal cords were collected and homogenized to detect the gene and protein expression of IL-10 and $\beta$-endorphin by using qRT-PCR and fluorescent immunoassays, respectively. As shown in Fig. 6B, intrathecal cynandione A specifically stimulated spinal mRNA expression of IL-10, which was not significantly reduced by intrathecal injection of the IL-10 neutralizing antibody or $\beta$ endorphin antiserum. On the other hand, cynandione $A$ also stimulated spinal mRNA expression of POMC, which was completely attenuated by the pretreatment with intrathecal injection of the IL-10 antibody ( $P<0.05$, by one-way ANOVA followed by the post-hoc Student-Newman-Keuls test) but not the $\beta$-endorphin antiserum (Fig. 6C). In addition, as shown in Fig. 6D and 6E, intrathecal injection of cynandione A stimulated IL-10 and $\beta$-endorphin expression; pretreatment with the IL-10 antibody neutralized IL-10 secreted and inhibited the expression of $\beta$-endorphin $(P<0.05$, by one-way ANOVA followed by the post-hoc Student-Newman-Keuls test). However, pretreatment with intrathecal injection of the $\beta$-endorphin antiserum neutralized $\beta$-endorphin (but not IL-10) secreted $(P<0.05$, by one-way ANOVA followed by the post-hoc Student-Newman-Keuls test).

Furthermore, microglial cells from neonatal rats were treated with the IL-10 antibody $(4 \mu \mathrm{g} / \mathrm{mL})$ or $\beta$ endorphin antiserum (1:300) for 0.5 hours before cynandione $A(100 \mu \mathrm{M})$ treatment over 2 hours. As shown in Fig. 6F and 6G, treatment with cynandione A stimulated the mRNA expression of IL-10 and POMC in cultured primary microglial cells. Pretreatment with the IL-10 antibody did not significantly alter cynandione A-stimulated IL-10 mRNA expression but completely reduced its stimulation on POMC expression ( $P<0.05$, by one-way ANOVA followed by the post-hoc Student-Newman-Keuls test). On the other hand, pretreatment with the $\beta$-endorphin did not significantly alter the mRNA expression of IL-10 or POMC.

\section{Cynandione A produced mechanical antiallodynia in neuropathic pain through activation of spinal a7 nAChRs}

In order to illustrate whether cynandione A-induced mechanical antiallodynia was through activation of a7 $n A C h R s$, four groups of neuropathic rats ( $n=6$ per group) received intrathecal saline $(10 \mu \mathrm{L})$ or the 
specific a7 nAChR antagonist methyllycaconitine $(10 \mu \mathrm{g})$ [47] 30 minutes later followed by intrathecal the vehicle $(10 \mu \mathrm{L})$ or cynandione $A(100 \mu \mathrm{g})$. As shown in Fig. 7A, intrathecal injection of cynandione $A$ in the ipsilateral hindpaws produced time-dependent mechanical antiallodynia, which was nearly completely inhibited by intrathecal injection of methyllycaconitine $(p<0.05$, by repeated measures two-way ANOVA followed by the post-hoc Student-Newman-Keuls test), although it did not significantly alter baseline mechanical thresholds in both contralateral and ipsilateral hindpaws.

Another four groups of neuropathic rats ( $\mathrm{n}=6$ per group) that received the same intrathecal treatments as above were sacrificed to obtain spinal cords 1 hour after the last injection to detect the gene and protein expression of IL-10 and $\beta$-endorphin. As exhibited in Fig. 7B and 7C, intrathecal injection of cynandione A remarkably increased the mRNA expression of IL-10 and POMC in both contralateral and ipsilateral spinal cords, whereas intrathecal methyllycaconitine was not effective in reducing baseline IL-10 and POMC mRNA expression. However, pretreatment with intrathecal methyllycaconitine entirely blocked cynandione A-stimulated mRNA expression of IL-10 or POMC ( $p<0.05$, by one-way ANOVA followed by the post-hoc Student-Newman-Keuls test). In addition, intrathecal injection of cynandione A in both contralateral and ipsilateral cords also stimulated the expression of IL-10 and $\beta$-endorphin, which was entirely attenuated by the pretreatment with intrathecal methyllycaconitine $(p<0.05$, by one-way ANOVA followed by the post-hoc Student-Newman-Keuls test; Fig. 7D, 7E).

Cultured primary microglial cells were pretreated with the vehicle or methyllycaconitine (100 nM [48]) 30 minutes later followed by cynandione A $(100 \mu \mathrm{M})$ over 2 hours. The cultured cells and culture medium were collected to measure the gene and protein expression of IL-10 and $\beta$-endorphin. As shown in Fig. 7F and $7 G$, treatment with cynandione $A$ in cultured primary microglial cells stimulated the mRNA expression of IL-10 and POMC, which was totally blocked by the pretreatment with methyllycaconitine $(p<0.05$, by one-way ANOVA followed by the post-hoc Student-Newman-Keuls test), although it did not significantly alter baseline expression of IL-10 or POMC. In addition, cynandione A treatment also stimulated the expression of IL-10 and $\beta$-endorphin, which was completely inhibited by pretreatment with methyllycaconitine $(p<0.05$, by one-way ANOVA followed by the post-hoc Student-Newman-Keuls test; Fig. 7H, 7I).

\section{Cynandione A stimulated spinal microglial expression of IL-10 and $\beta$-endorphin through the CAMP/PKA/p38/CREB signaling}

To explore whether the cAMP/PKA/p38/CREB signaling was responsible for cynandione A-induced mechanical antiallodynia in neuropathic pain and spinal expression of IL-10/ $\beta$-endorphin, two groups of neuropathic rats ( $n=6$ per group) received intrathecal injection of saline $(10 \mu \mathrm{L})$ or the specific adenylyl cyclase inhibitor DDA (20 $\mu$ g, dosage of which was based on the previous study [49]) 30 minutes later followed by intrathecal injection of cynandione A $(100 \mu \mathrm{g})$. Intrathecal injection of cynandione A in the ipsilateral hindpaws produced time-dependent mechanical antiallodynia, which was entirely blocked by the pretreatment with intrathecal DDA ( $p<0.05$, by repeated measures two-way ANOVA followed by the post-hoc Student-Newman-Keuls test), although it did not significantly alter the baseline mechanical 
thresholds (Fig. 8A). Additional three groups of neuropathic rats ( $n=6$ per group) that received the same intrathecal treatments as above except for addition of one control group were sacrificed 1 hour after the last injection. The spinal cord was collected and homogenized to detect gene expression of IL-10 and $\beta$ endorphin by using qRT-PCR. As shown in Fig. 8B and 8C, intrathecal injection of cynandione $A$ stimulated spinal mRNA expression of IL-10 and POMC, which was completely reduced by the pretreatment with intrathecal DDA ( $p<0.05$, by one-way ANOVA followed by the post-hoc StudentNewman-Keuls test). In addition, cultured primary microglial cells were pretreated with saline or DDA $(100 \mu \mathrm{M}[49]) 30$ minutes before cynandione A treatment $(100 \mu \mathrm{M})$ for 2 hours. Treatment with cynandione $A$ in microglial cells stimulated the mRNA expression of IL-10 and POMC, which was inhibited by the pretreatment with DDA ( $p<0.05$, by one-way ANOVA followed by the post-hoc Student-NewmanKeuls test; Fig. 8D, 8E).

In addition, four groups of neuropathic rats ( $\mathrm{n}=6$ per group) received intrathecal injection of saline (10 $\mu \mathrm{L})$ or the specific PKA activation inhibitor $\mathrm{H}-89(5 \mu \mathrm{g}$, dosage of which was based on the previous study [50]) 30 minutes before intrathecal injection of the vehicle $(10 \mu \mathrm{L})$ or cynandione $A(100 \mu \mathrm{g})$. As shown in Fig. 9A, pretreatment with intrathecal injection of $\mathrm{H}-89$ did not significantly alter the baseline mechanical thresholds, but completely blocked cynandione A-induced mechanical antiallodynia $(p<0.05$, by repeated measures two-way ANOVA followed by the post-hoc Student-Newman-Keuls test). In additional 4 groups of neuropathic rats ( $n=6$ per group), pretreatment with $\mathrm{H}-89$ also reduced cynandione A-stimulated spinal mRNA expression of IL-10 and POMC ( $<<0.05$, by one-way ANOVA followed by the post-hoc StudentNewman-Keuls test), although it did not significantly affect the baseline expression of IL-10 and POMC (Fig. 9B, 9C). Furthermore, treatment with cynandione A (100 $\mu \mathrm{M})$ stimulated the mRNA expression of IL10 and POMC in cultured primary microglial cells. Pretreatment (30 minute earlier) with H-89 (10 $\mu \mathrm{M}[50])$ completely hindered cynandione A-stimulated but not baseline expression of IL-10 or POMC $(p<0.05$, by one-way ANOVA followed by the post-hoc Student-Newman-Keuls test; Fig. 9D, 9E).

Furthermore, three groups of neuropathic rats ( $n=6$ per group) received intrathecal injection of saline (10 $\mu \mathrm{L})$ or the specific p38 mitogen-activated protein kinase (MAPK) activation inhibitor SB203580 (10 $\mu \mathrm{g}$, dosage of which was based on the previous study [51]) 30 minutes later followed by intrathecal injection of the vehicle $(10 \mu \mathrm{L})$ or cynandione $\mathrm{A}(100 \mu \mathrm{g})$. Mechanical thresholds in both contralateral and ipsilateral hindpaws were measured 1 hour after the last injection. As displayed in Fig. 10A, intrathecal injection of cynandione A produced time-dependent mechanical antiallodynia, which was completely alleviated by the pretreatment with intrathecal SB203580 $(p<0.05$, by repeated measures two-way ANOVA followed by the post-hoc Student-Newman-Keuls test; Fig. 10A). The rats were sacrificed immediately after the completion of the behavioral test and spinal cords were collected and homogenized. As exhibited, intrathecal injection of cynandione A stimulated the spinal mRNA expression of IL-10 (Fig. 10B) and POMC (Fig. 10C) as well as protein expression of IL-10 (Fig. 10D), which was entirely inhibited by the pretreatment with intrathecal SB203580 $(p<0.05$, by one-way ANOVA followed by the post-hoc Student-Newman-Keuls test). In addition, treatment with cynandione A (100 $\mu \mathrm{M})$ in cultured primary microglial cells for 2 hours stimulated the mRNA expression of IL-10 and POMC, which was 
completely reversed by the pretreatment (30 minutes prior to) with SB203580 $(50 \mu \mathrm{M}[51])(\mathrm{p}<0.05$, by one-way ANOVA followed by the post-hoc Student-Newman-Keuls test; Fig. 10E, 10F).

Lastly, two groups of neuropathic rats ( $n=6$ per group) received intrathecal injection of saline $(10 \mu \mathrm{L})$ or the specific CREB activation inhibitor KG501 (10 $\mu \mathrm{g}$ [51]) 30 minutes later followed by intrathecal injection of cynandione A (100 $\mu \mathrm{g})$. As presented in Fig. 11A, intrathecal injection of cynandione A produced time-dependent mechanical antiallodynia, which was completely blocked by the pretreatment with intrathecal KG501 $(p<0.05$, by repeated measures two-way ANOVA followed by the post-hoc Student-Newman-Keuls test). Additional three groups of neuropathic rats ( $n=6$ per group) received intrathecal injection of saline $(10 \mu \mathrm{L})$ or KG50130 minutes later followed by intrathecal injection of cynandione A $(100 \mu \mathrm{g})$ and the spinal cords were collected 1 hour after the last intrathecal injection. As shown, cynandione A- stimulated spinal gene expression of IL-10 and POMC was totally attenuated by the pretreatment with KG501 ( $<<0.05$, by one-way ANOVA followed by the post-hoc Student-NewmanKeuls test; Fig. 11B, 11C). Moreover, pretreatment (30 minutes earlier) with KG501 (25 $\mu \mathrm{M}$ [51]) in cultured primary microglial cells completely alleviated $100 \mu \mathrm{M}$ cynandione A-promoted but not baseline gene expression of IL-10 and POMC ( $p<0.05$, by one-way ANOVA followed by the post-hoc Student-NewmanKeuls test; Fig. 11D, 11E).

\section{Cynandione A stimulated spinal microglial expression of $\beta$-endorphin through the IL-10/STAT3 signaling}

In order to illustrate the role of IL-10/STAT3 signaling in cynandione A-induced spinal microglial $\beta$ endorphin expression and mechanical antiallodynia, the spinal STAT3 phosphorylation was first measured. Four groups of neuropathic rats ( $n=6$ per group) received intrathecal injection of saline (10 $\mu \mathrm{L})$ or the PKA activation inhibitor $\mathrm{H}-89(5 \mu \mathrm{g}) 30$ minutes later followed by the vehicle $(10 \mu \mathrm{L})$ or cynandione $A(100 \mu \mathrm{g})$. The rats were sacrificed 1 hour after the last injection and the spinal cords were obtained for the detection of the STAT3 phosphorylation using western blot. Intrathecal injection of cynandione A stimulated spinal STAT3 phosphorylation. Pretreatment with intrathecal injection of $\mathrm{H}-89$ did not affect baseline phosphorylation of STAT3, but abolished cynandione A-stimulated STAT3 activation ( $p<0.05$, by one-way ANOVA followed by the post-hoc Student-Newman-Keuls test; Fig. 12A, 12B).

In addition, additional four groups of neuropathic rats ( $\mathrm{n}=6$ per group) that received intrathecal injection of saline $(10 \mu \mathrm{L})$ or the IL-10 antibody $(2 \mu \mathrm{g}) 30$ minutes later followed by intrathecal injection of the vehicle $(10 \mu \mathrm{L})$ or cynandione $\mathrm{A}(100 \mu \mathrm{g})$. The rats were sacrificed 1 hour after the last injection and the spinal cords were obtained to detect the STAT3 phosphorylation. As shown in Fig. 12C and 12D, pretreatment with the IL-10 antibody totally blocked cynandione A-stimulated but not baseline phosphorylation of STAT3 ( $<<0.05$, by one-way ANOVA followed by the post-hoc Student-Newman-Keuls test).

Furthermore, three groups of neuropathic rats ( $n=6$ per group) received intrathecal injection of saline (10 $\mu \mathrm{L})$ or the specific STAT3 activation inhibitor NSC74859 $(10 \mu \mathrm{g}$, dosage of which was based on the previous study [9]) 30 minutes before intrathecal injection of cynandione $A(100 \mu \mathrm{g})$. Cynandione $A$ 
intrathecal injection produced time-dependent mechanical antiallodynia, which was completely inhibited by the pretreatment with intrathecal injection of NSC74859 $(p<0.05$, by repeated measures two-way ANOVA followed by the post-hoc Student-Newman-Keuls test; Fig. 12E). Additional three groups of neuropathic rats ( $n=6$ per group) received the same intrathecal treatments as above. The rats were sacrificed 1 hour after the last injection and the spinal cords were obtained. As exhibited in Fig. 12F, pretreatment with intrathecal NSC74859 totally blocked cynandione A-stimulated spinal POMC expression ( $p<0.05$, by one-way ANOVA followed by the post-hoc Student-Newman-Keuls test). In addition, pretreatment (30 minutes earlier) with NSC74859 (10 $\mu \mathrm{M}[9])$ in cultured primary microglial cells inhibited $100 \mu \mathrm{M}$ cynandione A-stimulated but not baseline expression of POMC $(p<0.05$, by one-way ANOVA followed by the post-hoc Student-Newman-Keuls test, Fig. 12G).

\section{Cynandione A stimulated phosphorylation of PKA, p38, CREB and STAT3 following spinal a7 nAChR agonism}

In order to illustrate whether cynandione A activated PKA/p38/CREB/STAT3 signaling following a7 $n A C h R$ agonism, four groups of neuropathic rats ( $n=6$ per group) received saline $(10 \mu \mathrm{L})$ or methyllycaconitine $(10 \mu \mathrm{g}) 30$ minutes later followed by intrathecal injection of the vehicle $(10 \mu \mathrm{L})$ or cynandione $A(100 \mu \mathrm{g})$. The rats were sacrificed 1 hour after the last intrathecal injection and the spinal cords were obtained. Phosphorylation of PKA, p38, CREB and STAT3 was detected in the contralateral and ipsilateral spinal cords using western blot. As shown in Fig. 13A-13D, intrathecal injection of cynandione A stimulated phosphorylation of PKA, p38, CREB and STAT3 in the contralateral and ipsilateral spinal cords. Pretreatment with intrathecal injection of methyllycaconitine entirely blocked cynandione A-promoted but not baseline phosphorylation of PKA, p38, CREB, and STAT3 ( $p<0.05$, by one-way ANOVA followed by the post-hoc Student-Newman-Keuls test).

\section{Discussion}

Intrathecal injection of cynandione A has been demonstrated to produce mechanical antiallodynia and thermal antihyperalgesia in neuropathic pain through spinal expression of $\beta$-endorphin [39]. Our current study confirms it and further extends that cynandione $A$ induces expression of $\beta$-endorphin subsequently through spinal microglial expression of IL-10 and not in reverse. The notion is supported by the following facts: 1) Intrathecal injection of cynandione A stimulated spinal expression of IL-10 and $\beta$-endorphin but not dynorphin $A$, measured by using qRT-PCR and fluorescent immunoassay kits. Furthermore, intrathecal cynandione A specifically stimulated IL-10 and $\beta$-endorphin expression in microglia, but not in astrocytes or neurons, in both contralateral and ipsilateral spinal cords of neuropathic rats, directly identified by double immunofluorescence staining. 2) Pretreatment with intrathecal injection of the IL-10 antibody in neuropathic rats eliminated cynandione A-induced spinal mechanical antiallodynia and gene expression of POMC but not IL-10. In addition, intrathecal $\beta$-endorphin antiserum also attenuated spinal cynandione A-induced mechanical antiallodynia but not gene expression of POMC or IL-10. On the other hand, intrathecal IL-10 antibody neutralized IL-10 secreted and inhibited the expression of $\beta$-endorphin, whereas intrathecal $\beta$-endorphin antiserum neutralized $\beta$-endorphin (but not IL-10) secreted. 3) Cynandione A 
treatment stimulated the expression of IL-10 and $\beta$-endorphin but not dynorphin A in primary cultures of microglia. 4) Pretreatment with the IL-10 antibody in cultured microglial cells completely inhibited cynandione A-stimulated gene expression of POMC but not IL-10, whereas the $\beta$-endorphin antiserum failed to affect cynandione A-stimulated gene expression of POMC or IL-10.

a7 nAChRs have been recognized to mediate long-term modification of cell functions, in addition to the typical ligand-gated ion channels that evoke cation-selective currents across the plasma membrane. Sustained stimulation of a7 nAChRs that mostly expressed in the central nervous system induces delayed cellular responses leading to neuroprotection and antinocieption via intracellular signal pathways probably triggered by $\mathrm{Ca}^{2+}$ influx, in addition to acute responses [52]. The a7 nAChR activationinduced antinoccieption has been demonstrated in animal models of pain hypersenstivity such as inflammatory pain, neuropathic pain and bone cancer pain [26-28]. It has been extensively reported that $\alpha 7$ nAChRs are colocalized on microglial cells as determined by qRT-PCR, western blot, immunofluorescent, and immunohistochemistry analyses and their activation is associated with antinociception and neuroprotection [29,53-55]. More specifically, it was recently identified that the spinal microglial IL-10/ß-endorphin pathway mediated the a7 nAChR agonists PHA-543613-, cinobufaginand lemairamin-induced antinociception in bone cancer pain and neuropathic pain [31, 32]. Our current study demonstrated that methyllycaconitine significantly blocked cynandione A-induced mechanical antiallodynia in neuroapthic rats, and the expression of IL-10 and $\beta$-endorphin in the spinal cords and cultured primary microglial cells. These results together reveal that cynandione A produces antinociception through a7 nAChR activation. The results further highlight the broad significance of the newly discovered spinal glial IL-10/ $\beta$-endorphin pathway in pain modulation, which is associated with electroacupuncture-, GLP-1 receptor-, GPR40- and a7 nAChR-induced antinociception [10-12]. On the other hand, activation of $a 7 \mathrm{nAChR}$ induces marked antineuroinflamation by inhibiting the expression of proinflammatory cytokines such as IL-1 $\beta$, IL- 6 and TNF-a $[53,54]$. Cynandione A has been demonstrated to reduce LPS-induced expression of TNF- $\alpha$, IL-6, IL-1 $\beta$, nitric oxide and prostaglandin E2 in BV-2 microglia, RAW264.7 macrophages and primary microglia, as well as in septic mice and neuropathic rats $[36,39,56]$. However, we previously hypothesized that the antineuroinflammatory property of cynandione A unlikely contributed to its antinociception, as the two effects were separately mediated by MAPKdependent and independent mechanisms [39]. In addition, the antineuroinflammatory effects of IL-10 and minocycline were separated from their antinociception in neuropathic pain $[9,44]$.

a7 nAChRs generate specific and complex $\mathrm{Ca}^{2+}$-dependent signals that include adenylyl cyclase, PKA, protein kinase $\mathrm{C}, \mathrm{Ca}^{2+}$-calmodulin-dependent kinase $[57,58]$, and phosphatidylinositol 3-kinase $[52,58]$, which trigger cell depolarization and turn on various functional switches [59]. It was reported that a7 nAChR and G-protein interaction regulated cAMP levels under LPS treatment in microglia [18]. In addition, nicotine stimulation led to PKA activation and further Raf-1/MEK/ERK1/2 and JAK2/STAT3 signaling through a7 nAChRs in human oral keratonocytes [30]. Specifically, the serine 365 in the M3-M4 cytoplasmic loop of the a7 nAChR has been demonstrated to be a phosphorylation site of PKA [60], though PKA is customarily activated by G-protein Gas [61]. In our current study, cynandion A stimulated 
PKA phosphorelation in a a7 nAChR-dependent manner, and the adenylate cyclase inhibitor DDA and PKA activation inhibitor $\mathrm{H}-89$ blocked cynandione A-induced spinal microglial expression of IL-10 and subsequent $\beta$-endorphin expreession. The results suggest that cynandione A stimulates microglial expression of IL-10 following a7 nAChR agonism through the cAMP/PKA signinaling.

As a transcription factor, CREB has been shown to be directly phosphorylated at Ser-133 by activated PKA in a classic way or indirectly through several other kinases particularly MAPKs including p38 [62]. It has been demonstrated that both classic Gs-cAMP/PKA/CREB and alternative Gs-cAMP/PKA/p38/CREB mediate GLP-1 receptor agonism-induced expression of M2 microglial biomarkers Arg 1, CD206, IL-4 and IL-10 [49]. a7 nAChR agonists biochemically characterized the pharmacological induction of CREB phosphorylation which was blocked by the pretreatment with methyllycaconitine [63]. a7 nAChR/Gprotein interaction was reported to attenuate $\mathrm{p} 38$ phosphorylation in microglia in a PTX-sensitive manner [18]. Activation of peripheral a7 nAChRs was also postulated to inhibit the CaMKIla/CREB signalling and block the expression of TNF-a and CGRP, thus contributing to antinociception $[64,65]$. It has been donmenstrated that a7 nAChR activation increased CREB phosphorylation in brain and improved cognitive function [66], but it is not known whether activation of a7 nAChRs stimultes CREB phosphorylation and relieves pain. Our results reveal that cynandione A-stimulated microglial IL-10/ $\beta$ endorphin expression is subsequently through CREB phosophrelation via p38 (or p38 $\beta$ ) activation alternatively. The notion is supported by the following findings in our current and previous studies [39]: 1) intrathecal cynandione A stimulated a7 nAChR-dependent spinal p38 and CREB activation in neuropathic rats; 2) cynandione $A$ upregulated phosphorylation of MAPKs including p38, ERK1/2 and JNK in cultured primary microglial cells; 3 ) cynandione A-stimulated IL-10/ $\beta$-endorphin expression in microglial cells was completely inhibited by the CREB activation inhibitor KG501 and p38 activation inhibitor SB203580 (but not by the ERK $1 / 2$ or JNK activation inhibitors). In addition, knockdown of spinal p38 $\beta$ but not $p 38 a$ using siRNAs also completely blocked cynandione A-induced $\beta$-endorphin expression; 4) cynandione Ainduced mechnical antiallodynia was totally attneuated by SB203580 and KG501.

IL-10 has been considered one of the most important antiinflammatory cytokines so far, by binding to the IL-10 receptor-a followed by activating IL-10 receptor- $\beta$ localized on the cell membrane $[67,68]$ and inhibiting the release of proinflammatory mediators, including TNF- $\alpha$, IL-1 $1 \beta$, IL-6, IL-8, G-CSF, and GM-CSF from monocytes, macrophages and microglia $[9,69,70]$. Additionally, exogenous IL-10 exhibites antinociception in pain hypersensitivity induced by peripheral nerve injury[10,11,70], paclitaxel treatment [71] and severe traumatic brain injury [72]. It has been demonstated the IL-10/JAK/STAT3 pathway in microglia mediates IL-10-stimulated $\beta$-endorphin expression, which is in parallel to its inhibition of expression of neuroinflammatory cytokines through antiinflammatory elements $[9,10]$. We thus postulate that cynandione A stimulates $\beta$-endorphin expression through autocrime IL-10 expression via the STAT3 signaling. Activation of a7 nAChRs indeed led to reducing inflammatory drive through a JAK2-STAT3 pathway that couples with CREB/Irs2/Akt survival signaling in the mouse islets [73]. a7 nAChR activation increased hypothalamic POMC expression by triggering JAK2/STAT3 pathway [74]. Consistently, our current study demonstrated that cynandione A stimulated microglial STAT3 activation which could be blocked by the a7 nAChR antagonist methyllycaconitine, PKA activation inhibitor H-89 and IL-10 
neutralizing antibody. Moreover, the STAT3 activation inhibitor NSC74859 also completely attenuated cyanandione A-induced expression of $\beta$-endorphin in the spinal cords of neuropathic rats and in cultured primary microglial cells.

\section{Conclusion}

Cynandione A produces mechancal antiallodynia in neuropathic pain through spinal a7 nAChR activation. The subsequent mechanisms invovlve microglial IL-10 expression via the cAMP/PKA/p38/CREB signaling and subsequent $\beta$-endorphin expression via the autocrime IL-10/STAT3 signaling. The proposed mechansms underlying cynandione A-induced mechanical antiallodynia in neuropathic pain is exhibited in Fig. 14.

\section{Abbreviations}

IL-10, interleukin-10; DMSO, dimethyl sulfoxide; MAPK, mitogen-activated protein kinase; a7 nAChR, a7 nicotinic acetylcholine receptor; PDYN, prodynorphin; PEG, polyethylene glycol; POMC, proopiomelanocortin; GFAP

Glial fibrillary acid protein; NeuN, neuronal specific nuclear protein; Iba-1, ionized calcium binding adaptor molecule-1; PBS, phosphate-buffered saline; SDS-PAGE, sodium dodecyl sulfatepolyacrylamide gel electrophoresis;GLP-1, glucagon-like peptide-1; GPR40, G protein-coupled receptor 40; FBS, fetal bovine serum; STAT3, signal transducer and activator of transcription 3.

\section{Declarations}

\section{Acknowledgements}

Not applicable.

\section{Funding}

This study was supported in part by a grant (\#81673403) from the National Natural Science Foundation of China.

\section{Availability of data and materials}

All data supporting the conclusion of the article are included in this article.

\section{Author contributions}


QQH and YXW conceived and designed the experiments; QQH, MY, ZYW, HL and JPA performed the experiments; QQH, MY and YXW analyzed the data; $Y X W$ and QQH wrote the paper. All authors read and approved the final manuscript.

\section{Ethics approval}

All animal experimental protocols and procedures in this study were reviewed and approved by the Animal Care and Welfare Committee of Shanghai Jiao Tong University and carried out in accordance with the animal care guidelines of the National Institutes of Health. The consent to participate is not applicable.

\section{Consent for publication}

Not applicable

\section{Competing interests}

The authors declare no competing financial interests in this work.

\section{Author details}

${ }^{1}$ King's Lab, Shanghai Jiao Tong University School of Pharmacy, Shanghai 200240, China. ${ }^{2}$ Jiangsu Key Laboratory for the Research and Utilization of Plants Resources, Institute of Botany, Jiangsu Province and Chinese Academy of Sciences, Nanjing 210014, China. ${ }^{3}$ State Key Laboratory of Oncogenes and Related Genes, Shanghai Cancer Institute, Shanghai Jiao Tong University, Shanghai 200232, China.

\section{References}

1. Jesus EE, V,Pinheiro AM, Santos A B,Freire SM, Tardy MB, El-Bacha RS, Costa SL. Costa M F D. Effects of IFN-gamma, TNF-alpha, IL-10 and TGF-beta on Neospora caninum infection in rat glial cells. Exp Parasitol. 2013;133(3):269-74.

2. Jankovic $D$, Kugler $D G$, Sher A. IL-10 production by $C D 4(+)$ effector T cells: a mechanism for selfregulation. Mucosal Immunol. 2010;3(3):239-46.

3. Asadullah K, Sterry W, Volk HD. Interleukin-10 therapy - Review of a new approach. Pharmacol Rev. 2003;55(2):241-69. 
4. Bastien D, Lacroix S. Cytokine pathways regulating glial and leukocyte function after spinal cord and peripheral nerve injury. Exp Neurol. 2014;258:62-77.

5. Wagner R, Janjigian M, Myers RR. Anti-inflammatory interleukin-10 therapy in CCI neuropathy decreases thermal hyperalgesia, macrophage recruitment, and endoneurial TNF-alpha expression. Pain. 1998;74(1):35-42.

6. Johnston IN, Milligan ED, Wieseler-Frank J, Frank MG, Zapata V,Campisi J, Langer S, Martin D,Green P,Fleshner M, Leinwand L, Maier SF. Watkins L R. A role for proinflammatory cytokines and fractalkine in analgesia, tolerance, and subsequent pain facilitation induced by chronic intrathecal morphine. J Neurosci. 2004;24(33):7353-65.

7. Poole S, Cunha F Q,Selkirk S, Lorenzetti BB, Ferreira SH. Cytokine-mediated inflammatory hyperalgesia limited by interleukin-10. Brit J Pharmacol. 1995;115(4):684-8.

8. Iwasa T, Afroz S, Inoue M, Arakaki R,Oshima M, Raju R. Waskitho A,Inoue M,Baba O,Matsuka Y. IL-10 and CXCL2 in trigeminal ganglia in neuropathic pain. Neurosci Lett. 2019;703:132-8.

9. Wu HY, Mao X F,Tang X Q,Ali U,Apryani E,Liu H,Li XY, Wang YX. Spinal interleukin-10 produces antinociception in neuropathy through microglial $\beta$-endorphin expression, separated from antineuroinflammation. Brain Behav Immun. 2018;73:504-19.

10. Wu HY, Tang X Q,Mao XF, Wang YX. Autocrine Interleukin-10 Mediates Glucagon-Like Peptide-1 Receptor-Induced Spinal Microglial $\beta$-Endorphin Expression. J Neurosci. 2017;37(48):11701-14.

11. Mao XF, Wu HY, Tang X Q,Ali U,Liu H,Wang YX. Activation of GPR40 produces mechanical antiallodynia via the spinal glial interleukin-10/ $\beta$-endorphin pathway. J Neuroinflammation. 2019;16(1):84.

12. Ali U, Apryani E, Wu HY, Mao X F,Liu H,Wang YX. Low frequency electroacupuncture alleviates neuropathic pain by activation of spinal microglial IL-10/ $\beta$-endorphin pathway. Biomed Pharmacother. 2020; 125(109898.

13. Nemecz A, Prevost MS, Menny A,Corringer PJ. Emerging Molecular Mechanisms of Signal Transduction in Pentameric Ligand-Gated Ion Channels. Neuron. 2016;90(3):452-70.

14. Sabri O, Becker GA, Meyer PM, Hesse S, Wilke S, Graef S,Patt M, Luthardt J, Wagenknecht G, Hoepping A,Smits RFranke A,Sattler B, Habermann B, Neuhaus P, Fischer S, Tiepolt S, Deuther-Conrad W. Barthel H,Schonknecht P,Brust P. First-in-human PET quantification study of cerebral alpha4beta2* nicotinic acetylcholine receptors using the novel specific radioligand (-)-[(18)F]Flubatine. Neuroimage. 2015;118:199-208.

15. Liu Y, Zeng X,Hui Y, Zhu CWu J, Taylor DH, Ji J. Fan W,Huang Z,Hu J. Activation of alpha7 nicotinic acetylcholine receptors protects astrocytes against oxidative stress-induced apoptosis: implications for Parkinson's disease. Neuropharmacology. 2015;91:87-96.

16. Suzuki T, Hide I,Matsubara A,Hama C,Harada K, Miyano K,Andra M, Matsubayashi H, Sakai N, Kohsaka S, Inoue K, Nakata Y. Microglial alpha7 nicotinic acetylcholine receptors drive a phospholipase C/IP3 pathway and modulate the cell activation toward a neuroprotective role. J Neurosci Res. 2006;83(8):1461-70. 
17. Hawkins BT, Egleton RD, Davis TP. Modulation of cerebral microvascular permeability by endothelial nicotinic acetylcholine receptors. Am J Physiol Heart Circ Physiol. 2005;289(1):H212-9.

18. King JR, Gillevet TC, Kabbani N. A G protein-coupled alpha7 nicotinic receptor regulates signaling and TNF-alpha release in microglia. Febs Open Bio. 2017;7(9):1350-61.

19. Parri HR, Hernandez CM, Dineley KT. Research update: Alpha7 nicotinic acetylcholine receptor mechanisms in Alzheimer's disease. Biochem Pharmacol. 2011;82(8):931-42.

20. Morioka N, Harano S, Tokuhara M,Idenoshita Y,Zhang FF, Hisaoka-Nakashima K, Nakata Y. Stimulation of a7 nicotinic acetylcholine receptor regulates glutamate transporter GLAST via basic fibroblast growth factor production in cultured cortical microglia. Brain Res. 2015;1625:111-20.

21. Xu S, Yang B,Tao T,ZhangJLiu Y,Hu J,Fan Y, Zhang G. Activation of a7-nAChRs protects SH-SY5Y cells from 1-methyl-4-phenylpyridinium-induced apoptotic cell death via ERK/p53 signaling pathway. J Cell Physiol. 2019;234(10):18480-91.

22. Wang $Y$, Jiang Q,Xia YY, Huang ZH, Huang C. Involvement of alpha7nAChR in electroacupuncture relieving neuropathic pain in the spinal cord of rat with spared nerve injury. Brain Res Bull. 2018;137:257-64.

23. Ji L, Chen Y, Wei HFeng H, Chang R,YuDWang X, Gong X,Zhang M. Activation of alpha7 acetylcholine receptors reduces neuropathic pain by decreasing dynorphin A release from microglia. Brain Res. 2019;1715:57-65.

24. Sun R, Liu Y, Hou B,Lei Y,BoJ, Zhang W,Sun Y, Zhang YZhang Z,Liu Z,Huo W. Mao Y,Ma Z,Gu X. Perioperative activation of spinal alpha7 nAChR promotes recovery from preoperative stress-induced prolongation of postsurgical pain. Brain Behav Immun. 2019;79:294-308.

25. Bagdas D, Sonat F A,Hamurtekin E,Sonal S,Gurun MS. The antihyperalgesic effect of cytidine-5 'diphosphate-choline in neuropathic and inflammatory pain models. Behav Pharmacol. 2011;22(56):589-98.

26. Kiguchi N, Kobayashi Y, Maeda T,Tominaga SNakamura J, Fukazawa Y,Ozaki M,Kishioka S. Activation of nicotinic acetylcholine receptors on bone marrow-derived cells relieves neuropathic pain accompanied by peripheral neuroinflammation. Neurochem Int. 2012;61(7):1212-9.

27. Gong S, Liang Q, Zhu Q,Ding D,YinQ,TaoJ, Jiang X. Nicotinic acetylcholine receptor a7 subunit is involved in the cobratoxin-induced antinociception in an animal model of neuropathic pain. Toxicon. 2015;93:31-6.

28. Bagdas D, Wilkerson JL, Kulkarni A, Toma W,AISharari S,Gul Z,Lichtman AH, Papke RL, Thakur GA. Damaj M I. The alpha7 nicotinic receptor dual allosteric agonist and positive allosteric modulator GAT107 reverses nociception in mouse models of inflammatory and neuropathic pain. $\mathrm{Br} \mathrm{J}$ Pharmacol. 2016;173(16):2506-20.

29. Zhang Q, Lu Y, Bian H, Guo L, Zhu H. Activation of the alpha7 nicotinic receptor promotes lipopolysaccharide-induced conversion of M1 microglia to M2. Am J Transl Res. 2017;9(3):971-85.

30. Arredondo J, Chernyavsky A I,Jolkovsky DL, Pinkerton K E,Grando SA. Receptor-mediated tobacco toxicity: cooperation of the Ras/Raf-1/MEK1/ERK and JAK-2/STAT-3 pathways downstream of 
alpha7 nicotinic receptor in oral keratinocytes. FASEB J. 2006;20(12):2093-101.

31. Apryani E, Ali U,Wang ZY, Wu H Y,Mao X F,Ahmad KA, Li XY, Wang YX. The spinal microglial IL-10/ $\beta-$ endorphin pathway accounts for cinobufagin-induced mechanical antiallodynia in bone cancer pain following activation of a7-nicotinic acetylcholine receptors. J Neuroinflammation. 2020;17(1):75.

32. Wang ZY, Han Q Q,Deng MY, Zhao MJ, Apryani E,Shoaib RM, Wei DQ, Wang YX. Lemairamin, isolated from the Zanthoxylum plants, alleviates pain hypersensitivity via spinal alpha7 nicotinic acetylcholine receptors. Biochem Biophys Res Commun. 2020;525(4):1087-94.

33. Gong SS, Liu CD, Liu SL, Du YR, Kang W,Dong XQ. Studies on constituents of the Chinese traditional drug baishouwu (Cynanchum auriculatum Royle ex Wight). Yao xue xue bao = Acta pharmaceutica Sinica. 1988; 23(4):276-280.

34. Hwang BY, Kim SE, Kim YH, Kim HS, Hong YS, Ro JS, Lee KS, Lee JJ. Pregnane glycoside multidrugresistance modulators from Cynanchum wilfordii. J Nat Prod. 1999;62(4):640-3.

35. Koo HJ, Sohn E-H,Pyo S, Woo HG, Park D W,Ham Y-M,Jang S-A, Park S-Y, Kang SC. An ethanol root extract of Cynanchum wilfordii containing acetophenones suppresses the expression of VCAM-1 and ICAM-1 in TNF-a-stimulated human aortic smooth muscle cells through the NF-KB pathway. Int $\mathrm{J}$ Mol Med. 2015;35(4):915-24.

36. Kim SH, Lee TH, Lee SM, Park JH, Park K H,Jung M, Jung H, Mohamed MA, Baek N I,Chung IS, Kim J. Cynandione $A$ attenuates lipopolysaccharide-induced production of inflammatory mediators via MAPK inhibition and NF-kappaB inactivation in RAW264.7 macrophages and protects mice against endotoxin shock. Exp Biol Med (Maywood). 2015;240(7):946-54.

37. Yue R, Yuan X,Liu X, Zhang JJiang P, He C,Shan L, Yu Y, Zhang W. Cynandione A mitigates ischemic injuries in rats with cerebral ischemia. J Neurochem. 2012;121(3):451-64.

38. Lee MK, Yeo H, Kim J, Markelonis GJ, Oh TH, Kim YC. Cynandione A from Cynanchum wilfordii protects cultured cortical neurons from toxicity induced by $\mathrm{H} 2 \mathrm{O} 2$, L-glutamate, and kainate. J Neurosci Res. 2000;59(2):259-64.

39. Huang Q, Mao XF, Wu HY, Liu H,Sun ML, Wang X,Wang YX. Cynandione A attenuates neuropathic pain through p38beta MAPK-mediated spinal microglial expression of beta-endorphin. Brain Behav Immun. 2017;62:64-77.

40. Busch-Dienstfertig M, Labuz D, Fau - Wolfram T, Wolfram T, Fau -. Vogel N N,Vogel Nn Fau - Stein C,Stein C. JAK-STAT1/3-induced expression of signal sequence-encoding proopiomelanocortin mRNA in lymphocytes reduces inflammatory pain in rats. 1744-8069 (Electronic)).

41. Sitte N, Busch M, Mousa SA, Labuz D,Rittner H, Gore C,Krause H. Stein C,Schafer M. Lymphocytes upregulate signal sequence-encoding proopiomelanocortin mRNA and beta-endorphin during painful inflammation in vivo. J Neuroimmunol. 2007;183(1-2):133-45.

42. Leitl MD, Onvani S, Bowers MS, Cheng K, Rice KC, Carlezon WA Jr, Banks ML, Negus SS. Pain-related depression of the mesolimbic dopamine system in rats: expression, blockade by analgesics, and role of endogenous kappa-opioids. Neuropsychopharmacology. 2014;39(3):614-24. 
43. Gong N,XiaoQ, Zhu B, Zhang CY, Wang Y C,Fan H,Ma AN, Wang YX. Activation of spinal glucagon-like peptide-1 receptors specifically suppresses pain hypersensitivity. J Neurosci. 2014;34(15):5322-34.

44. Huang Q, Mao XF, Wu HY, Li TF, Sun ML, Liu H,Wang YX. Bullatine A stimulates spinal microglial dynorphin A expression to produce anti-hypersensitivity in a variety of rat pain models. Journal of Neuroinflammation. 2016; 13(.

45. Huang JL, Chen XL, Guo C,Wang YX. Contributions of spinal D-amino acid oxidase to bone cancer pain. Amino Acids. 2012;43(5):1905-18.

46. Wang YX, Mao XF, Li TF, Gong N,Zhang MZ. Dezocine exhibits antihypersensitivity activities in neuropathy through spinal $\mu$-opioid receptor activation and norepinephrine reuptake inhibition. Sci Rep. 2017; 7(43137.

47. Escubedo E, Chipana C,Pérez-Sánchez M, Camarasa J, Pubill D. Methyllycaconitine prevents methamphetamine-induced effects in mouse striatum: involvement of alpha7 nicotinic receptors. $J$ Pharmacol Exp Ther. 2005;315(2):658-67.

48. van Goethem NP, Paes D,Puzzo D,Fedele E, Rebosio C,Gulisano W, Palmeri A, Wennogle LP,Peng Y,Bertrand D,Prickaerts J. Antagonizing a7 nicotinic receptors with methyllycaconitine (MLA) potentiates receptor activity and memory acquisition. Cellular Signalling. 2019; 62(109338.

49. Wu HY, Tang X Q,Liu H, Mao XF, Wang YX. Both classic Gs-CAMP/PKA/CREB and alternative GscAMP/PKA/p38ß/CREB signal pathways mediate exenatide-stimulated expression of M2 microglial markers. J Neuroimmunol. 2018;316:17-22.

50. Wu HY, Mao X F,Fan H, Wang YX. p38beta Mitogen-Activated Protein Kinase Signaling Mediates Exenatide-Stimulated Microglial beta-Endorphin Expression. Mol Pharmacol. 2017;91(5):451-63.

51. Li TF, Wu HY, Wang YR, Li XY, Wang YX. Molecular signaling underlying bulleyaconitine A (BAA)induced microglial expression of prodynorphin. Sci Rep. 2017; 7(45056.

52. Kihara T, Shimohama S, Sawada H,Honda K. Nakamizo T,Shibasaki H,Kume T,Akaike A. alpha 7 nicotinic receptor transduces signals to phosphatidylinositol 3-kinase to block A beta-amyloidinduced neurotoxicity. J Biol Chem. 2001;276(17):13541-6.

53. Zhang W, Liu Y, Hou BL, Gu XP, Ma ZL. Activation of spinal alpha-7 nicotinic acetylcholine receptor attenuates remifentanil-induced postoperative hyperalgesia. Int J Clin Exp Med. 2015;8(2):1871-9.

54. Shytle RD, Mori T, Townsend K,Vendrame M, Sun N,Zeng J, Ehrhart J, Silver AA. Sanberg P R,Tan J. Cholinergic modulation of microglial activation by alpha 7 nicotinic receptors. J Neurochem. 2004;89(2):337-43.

55. Shi S, Liang DL, Bao M, Xie YL, Xu WJ, Wang LY, Wang Z X,Qiao ZD. Gx-50 Inhibits Neuroinflammation via alpha 7 nAChR Activation of the JAK2/STAT3 and PI3K/AKT Pathways. J Alzheimers Dis. 2016;50(3):859-71.

56. Yang SB, Lee SM, Park JH, Lee TH, Baek NI, Park HJ, Lee H, Kim J. Cynandione A from Cynanchum wilfordii attenuates the production of inflammatory mediators in LPS-induced BV-2 microglial cells via NF-кB inactivation. Biol Pharm Bull. 2014;37(8):1390-6. 
57. Allen CM, Ely CM, Juaneza MA, Parsons SJ. Activation of Fyn tyrosine kinase upon secretagogue stimulation of bovine chromaffin cells. J Neurosci Res. 1996;44(5):421-9.

58. Chan KM, Gordon T, Zochodne D W,Power HA. Improving peripheral nerve regeneration: From molecular mechanisms to potential therapeutic targets. Exp Neurol. 2014;261:826-35.

59. Albuquerque EX, Pereira EF, R,Alkondon M, Rogers SW. Mammalian Nicotinic Acetylcholine Receptors: From Structure to Function. Physiol Rev. 2009;89(1):73-120.

60. Charpantier E, Wiesner A,Huh KH, Ogier R, Hoda JC, Allaman G. Raggenbass M,Feuerbach D,Bertrand D,Fuhrer C. Alpha7 neuronal nicotinic acetylcholine receptors are negatively regulated by tyrosine phosphorylation and Src-family kinases. J Neurosci. 2005;25(43):9836-49.

61. Beaulieu JM, Gainetdinov RR. The physiology, signaling, and pharmacology of dopamine receptors. Pharmacol Rev. 2011;63(1):182-217.

62. Scott Bitner R. Cyclic AMP response element-binding protein (CREB) phosphorylation: a mechanistic marker in the development of memory enhancing Alzheimer's disease therapeutics. Biochem Pharmacol. 2012;83(6):705-14.

63. Wan D, Wang D,Sun Q,Song Y,Jiang Y, Li R, Ye J. Antinociception of spirocyclopiperazinium salt compound LXM-10-M targeting alpha7 nicotinic receptor and M4 muscarinic receptor and inhibiting CaMKIlalpha/CREB/CGRP signaling pathway in mice. Eur J Pharmacol. 2016;770:92-8.

64. Yang $H$, Sun Q, Liang Y, Jiang YLi R, Ye J. Antinociception of the spirocyclopiperazinium salt compound LXM-15 via activating alpha7 $\mathrm{nAChR}$ and $\mathrm{M} 4 \mathrm{mAChR}$ and inhibiting CaMKIlalpha/cAMP/CREB/CGRP signalling pathway in mice. Regul Toxicol Pharmacol. 2018;94:108-14.

65. Wang D, Yang H,Liang YY, Wang X,Du XL, Li RT, Jiang YM, Ye J. Antinociceptive Effect of Spirocyclopiperazinium Salt Compound DXL-A-24 and the Underlying Mechanism. Neurochem Res. 2019;44(12):2786-95.

66. Bitner RS, Bunnelle WH, Anderson DJ, Briggs C A,Buccafusco J, Curzon P,Decker M W,Frost JM, Gronlien JH, Gubbins ELi J, Malysz J, Markosyan S, Marsh K, Meyer MD, Nikkel AL, Radek RJ, Robb HM,Timmermann D, Sullivan JP. Gopalakrishnan M. Broad-spectrum efficacy across cognitive domains by alpha7 nicotinic acetylcholine receptor agonism correlates with activation of ERK1/2 and CREB phosphorylation pathways. J Neurosci. 2007;27(39):10578-87.

67. Scumpia PO, Moldawer LL. Biology of interleukin-10 and its regulatory roles in sepsis syndromes. Crit Care Med. 2005;33(12):468-71.

68. Sabat R, Grutz G, Warszawska K, Kirsch S. Witte E,Wolk K,Geginat J. Biology of interleukin-10. Cytokine Growth F R. 2010;21(5):331-44.

69. de Waal Malefyt R, Abrams J, Bennett B, Figdor CG, de Vries JE. Interleukin 10(IL-10) inhibits cytokine synthesis by human monocytes: an autoregulatory role of IL-10 produced by monocytes. J Exp Med. 1991;174(5):1209-20.

70. Lee BS, Jun IG, Kim SH, Park JY. Intrathecal Gabapentin Increases Interleukin-10 Expression and Inhibits Pro-Inflammatory Cytokine in a Rat Model of Neuropathic Pain. J Korean Med Sci. 
2013;28(2):308-14.

71. Ledeboer A, Jekich B M,Sloane EM, Mahoney JH, Langer SJ, Milligan ED, Martin D,Maier SF, Johnson K W,Leinwand LA, Chavez RA. Watkins L R. Intrathecal interleukin-10 gene therapy attenuates paclitaxel-induced mechanical allodynia and proinflammatory cytokine expression in dorsal root ganglia in rats. Brain Behav Immun. 2007;21(5):686-98.

72. Csuka E, Morganti-Kossmann MC, Lenzlinger PM, Joller H, Trentz O,Kossmann T. IL-10 levels in cerebrospinal fluid and serum of patients with severe traumatic brain injury: relationship to IL-6, TNFalpha, TGF-beta1 and blood-brain barrier function. J Neuroimmunol. 1999;101(2):211-21.

73. Gupta D, Lacayo AA, Greene SM, Leahy JL, Jetton. T L. beta-Cell mass restoration by alpha7 nicotinic acetylcholine receptor activation. J Biol Chem. 2018;293(52):20295-306.

74. Souza CM, do Amaral CL, Souza S, C,de Souza AC, P,de Cassia Alves Martins I, Contieri LS, Milanski M, Torsoni AS, Ignacio-Souza LM. Torsoni M A. JAK2/STAT3 Pathway is Required for alpha7nAChRDependent Expression of POMC and AGRP Neuropeptides in Male Mice. Cell Physiol Biochem. 2019;53(4):701-12.

\section{Figures}

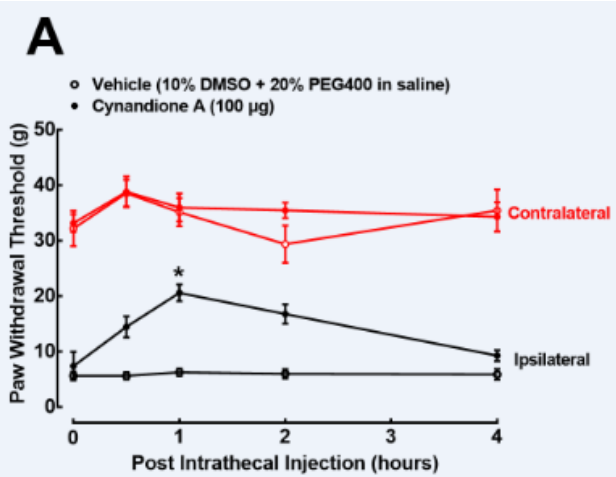

D

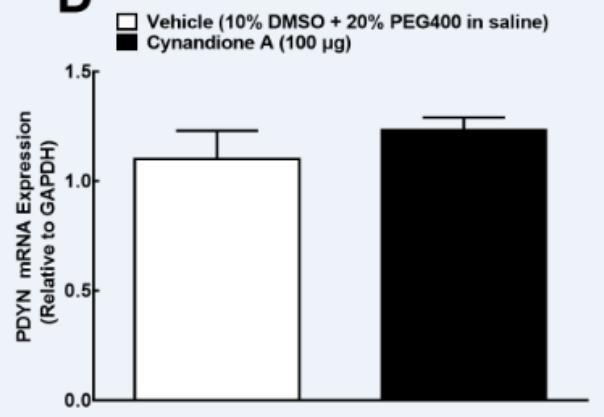

B

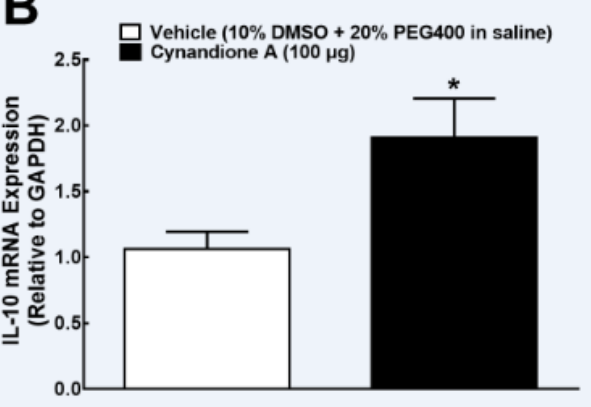

E

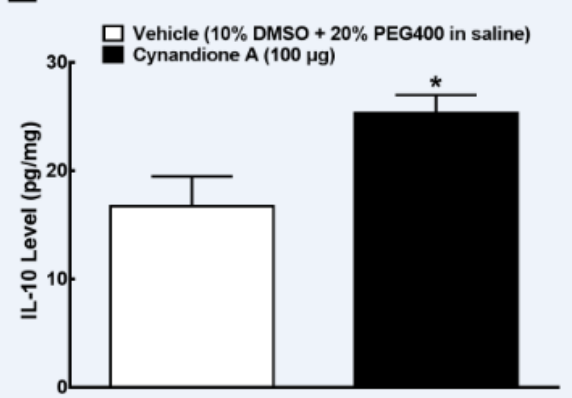

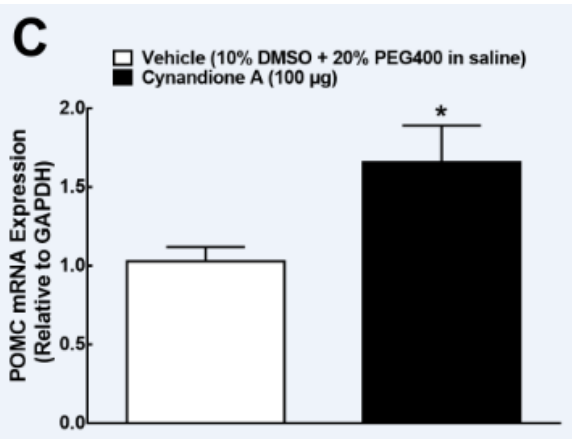

$\mathbf{F}$

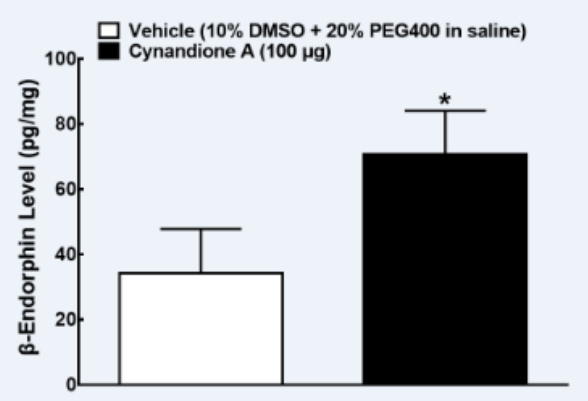

\section{Figure 1}

Effects of cynandione A, given intrathecally, on mechanical allodynia (A), spinal mRNA expression of IL10 (B), the $\beta$-endorphin precursor proopiomelanocortin (POMC, $C$ ) and dynorphin precursor prodynorphin (PDYN, D), and spinal protein expression of IL-10 (E) and $\beta$-endorphin (F) in neuropathic rats induced by L5/L6 spinal nerve ligation. Spinal lumbar enlargements (L3-L5) were obtained from the sacrificed rats 1 
hour after injection of cynandione $\mathrm{A}$ or the vehicle. The gene and protein expression was determined by using qRT-PCR and enzyme-linked immunosorbent fluorescent assays, respectively. Data are shown as means \pm SEM ( $n=6$ per group). ${ }^{*} p<0.05$ compared with the vehicle group, analyzed by two-tailed and unpaired Student t-test or repeated measures two-way ANOVA followed by the post-hoc Student-NewmanKeuls test.
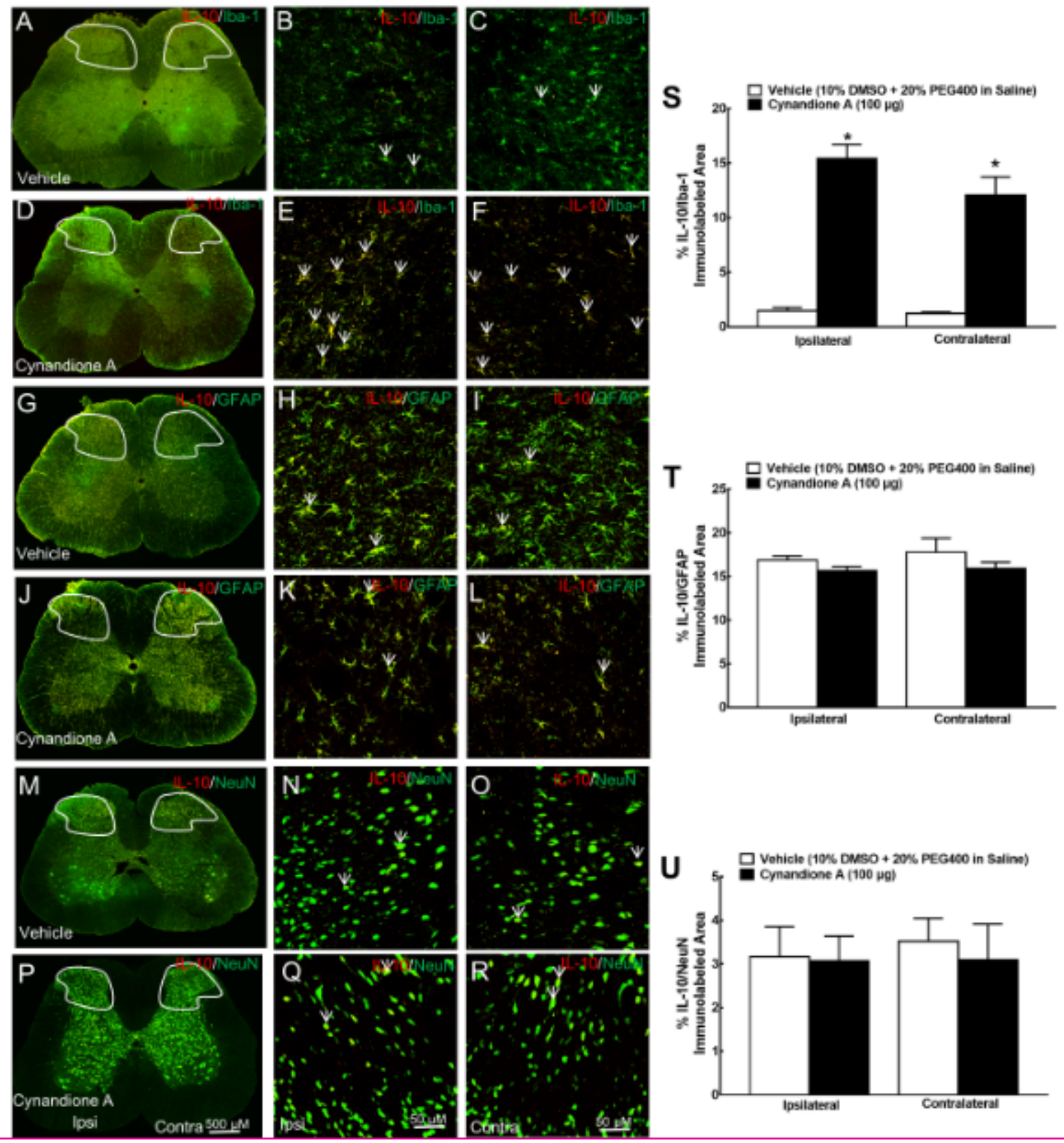

Figure 2

Specific stimulatory effects of cynandione A, given intrathecally, on spinal microglial expression of IL-10 in neuropathic rats induced by tight ligation of L5/L6 spinal nerves. Neuropathic rats that received intrathecal injection of cynandione $A$ or the vehicle were sacrificed 1 hour after injection and the spinal lumbar enlargements (L3-L5) were obtained. The specific expression of IL-10 was double fluorescence immunolabeled with the microglial cellular biomarker Iba-1, astrocytic cellular biomarker GFAP (G-L) and

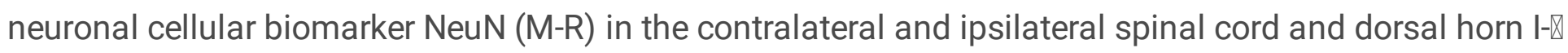


laminate. Arrows indicate yellow double labeling of IL-10 with the corresponding cellular biomarkers. The immunolabeled surface areas of IL-10/lba-1 (S), IL-10/GFAP (T) and IL-10/NeuN (U) from the indicated spinal dorsal horn laminae $\mathrm{I}-\mathbb{Q}$ were quantified using the Image $\mathrm{J}$ program. Data are presented as means \pm SEM ( $n=5$ per group). * $P<0.05$ compared with the vehicle group, analyzed by one-way ANOVA followed by the post-hoc Student-Newman-Keuls test.
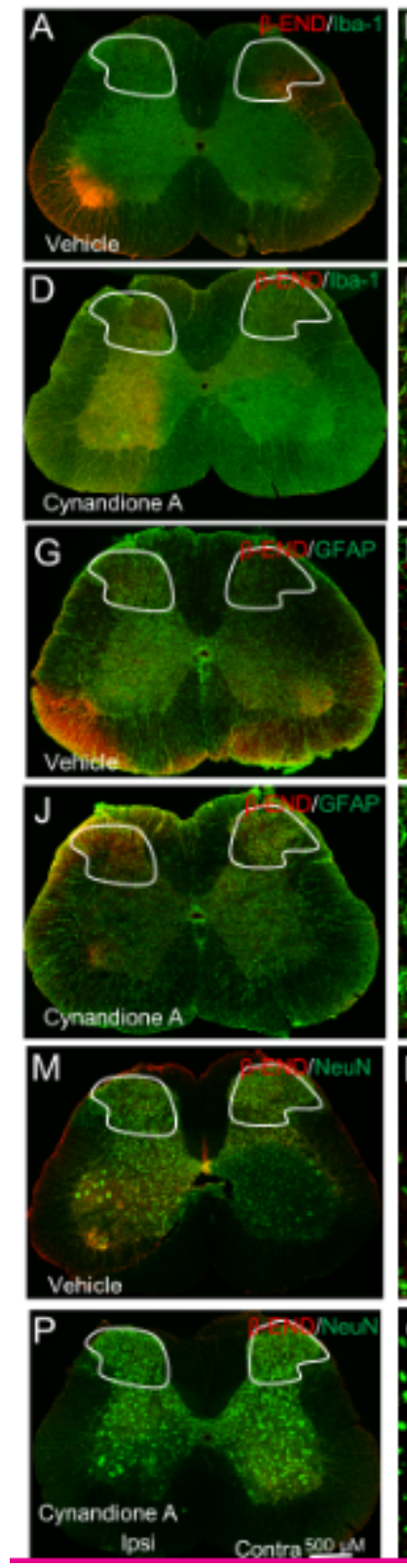
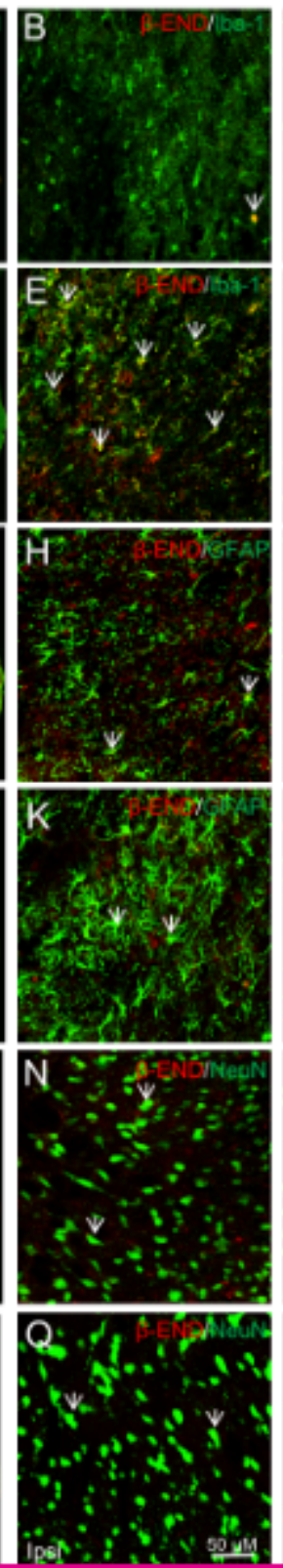
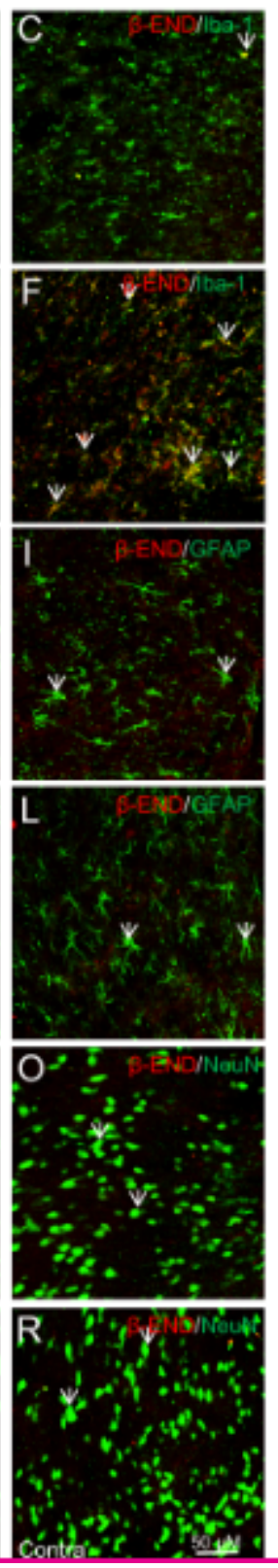
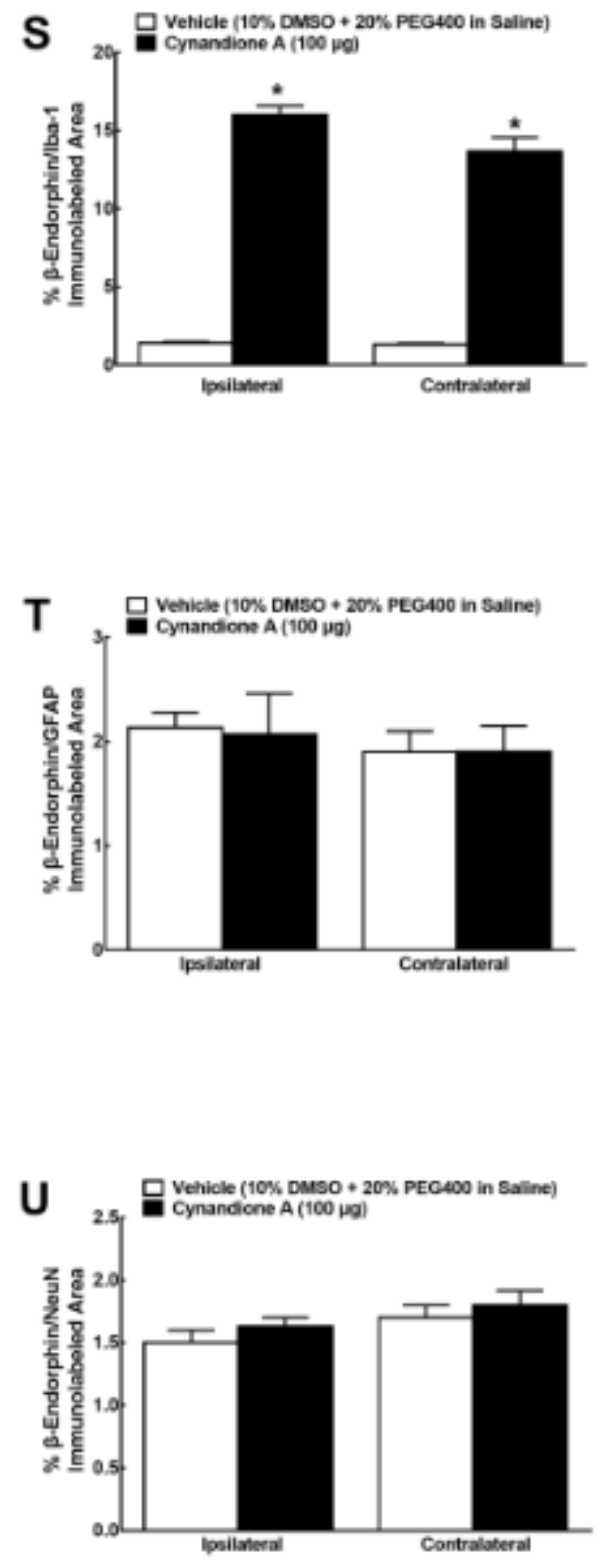

Figure 3

Specific stimulatory effects of cynandione A, given intrathecally, on spinal microglial expression of $\beta$ endorphin in neuropathic rats induced by tight ligation of L5/L6 spinal nerves. Neuropathic rats that received intrathecal injection of cynandione $A$ or the vehicle were sacrificed 1 hour after injection and the spinal lumbar enlargements (L3-L5) were obtained. The expression of $\beta$-endorphin was double fluorescence immunolabeled with the microglial cellular biomarker Iba-1, astrocytic cellular biomarker GFAP (G-L) and neuronal cellular biomarker NeuN (M-R) in the contralateral and ipsilateral spinal cord 
and dorsal horn I- $\mathrm{Q}$ laminate. Arrows indicate yellow double labeling of $\beta$-endorphin with the corresponding cellular biomarkers. The immunolabeled surface areas of $\beta$-endorphin/lba-1 (S), $\beta$ -

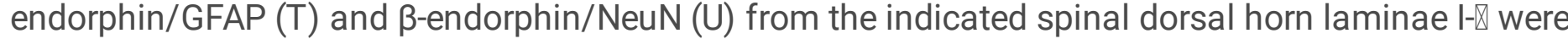
quantified using the Image $J$ program. Data are presented as means \pm SEM $\left(n=5\right.$ per group). ${ }^{*}<<0.05$ compared with the vehicle group, analyzed by one-way ANOVA followed by the post-hoc StudentNewman-Keuls test.
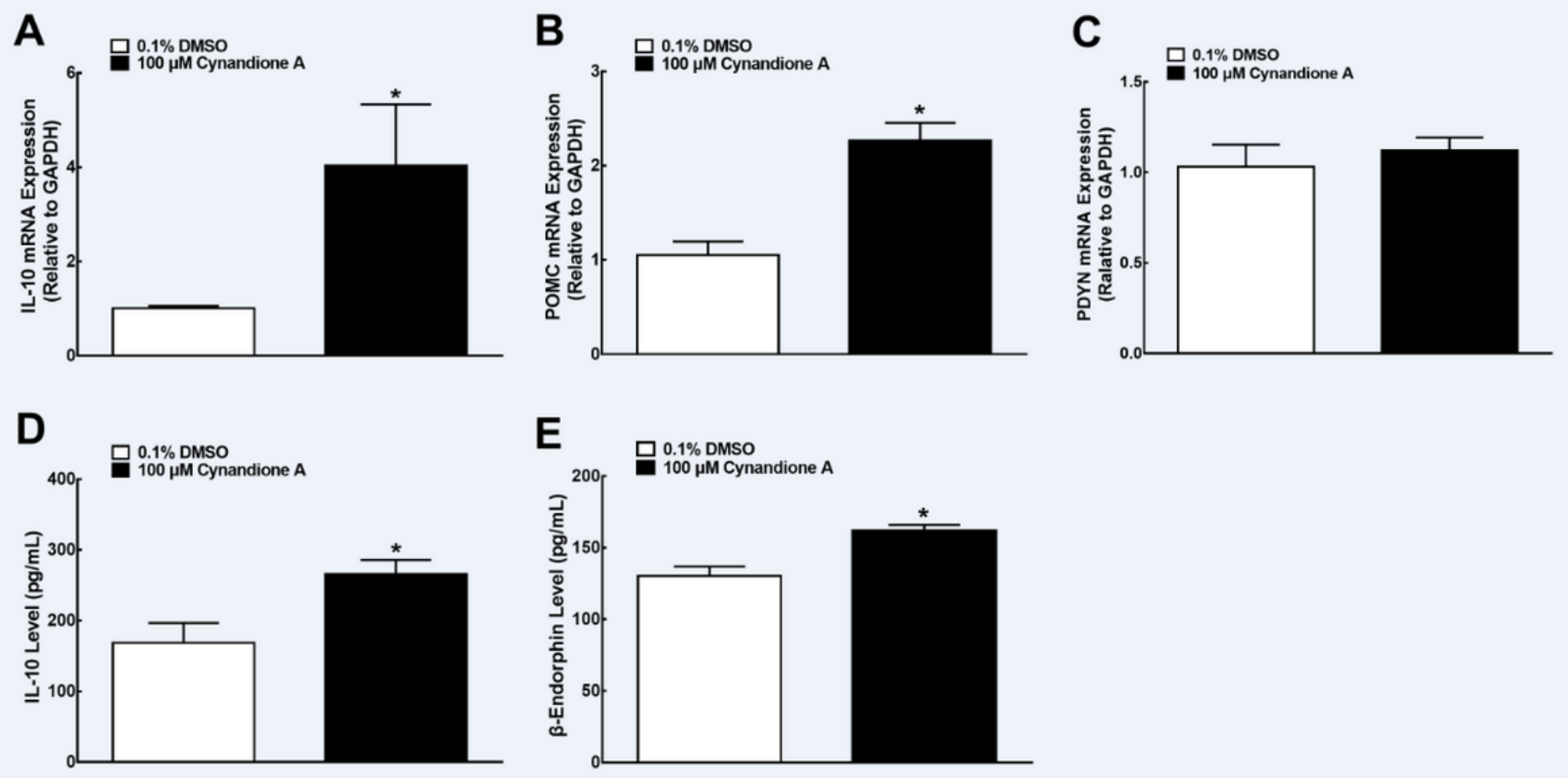

\section{Figure 4}

Effects of cynandione $A$ on the gene expression of IL-10 (A), the $\beta$-endorphin precursor proopiomelanocortin (POMC, B) and dynorphin precursor prodynorphin (PDYN, C), as well as protein expression of IL-10 (D) and $\beta$-endorphin (E) in primary cultures of microglia. Primary microglial cells, collected from 1-day-old neonatal rats, were incubated with cynandione A for 2 hours and they and the culture medium were collected later. The gene and protein expression of IL-10, $\beta$-endorphin and dynorphin A was determined using qRT-PCR and enzyme-linked immunosorbent fluorescent assays, respectively. The data are presented as means \pm SEM ( $n=3$ per group with two independent repeats). ${ }^{*} p<0.05$ compared with the vehicle group, by two-tailed and unpaired Student t-test. 

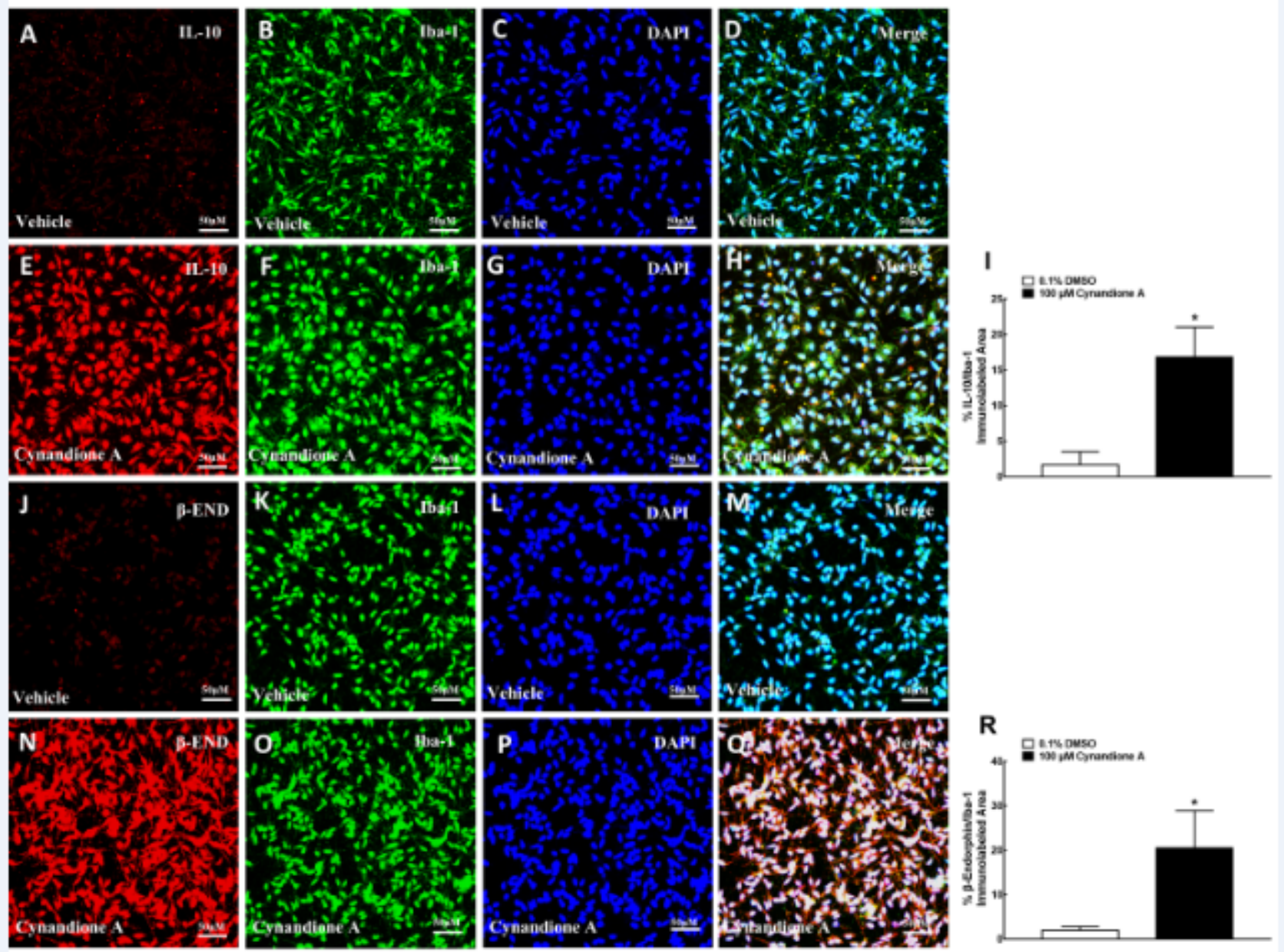

\section{Figure 5}

Stimulatory effects of cynandione A on the expression of IL-10 (A-I) and $\beta$-endorphin (J-R) in cultured primary microglia originated from 1-day-old neonatal rats. Cultured primary microglia were collected 2 hours after cynandione A incubation and immunofluorescence was triply stained with IL-10 (red)/Iba-1 (green)/DAPI (blue) or $\beta$-endorphin (red)/lba-1 (green)/DAPI (blue). The immunolabeled surface areas of IL-10/Iba-1 (I) and $\beta$-endorphin/Iba-1 (R) from microglial cells were quantified by using the Image $\mathrm{J}$ program. Data are presented as means \pm SEM ( $n=3$ per group with two independent repeats). ${ }^{*}<0.05$ compared with the control group, analyzed by two-tailed and unpaired Student t-test. 
A

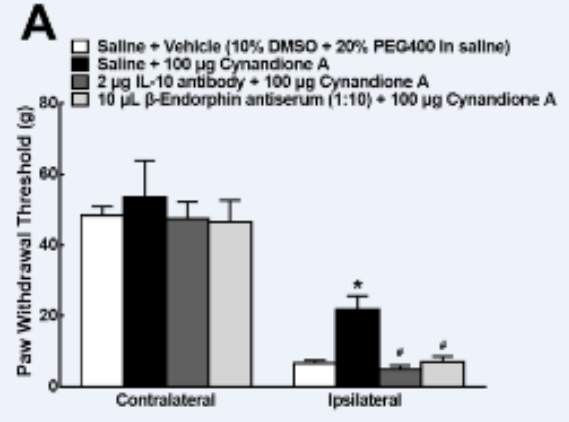

D
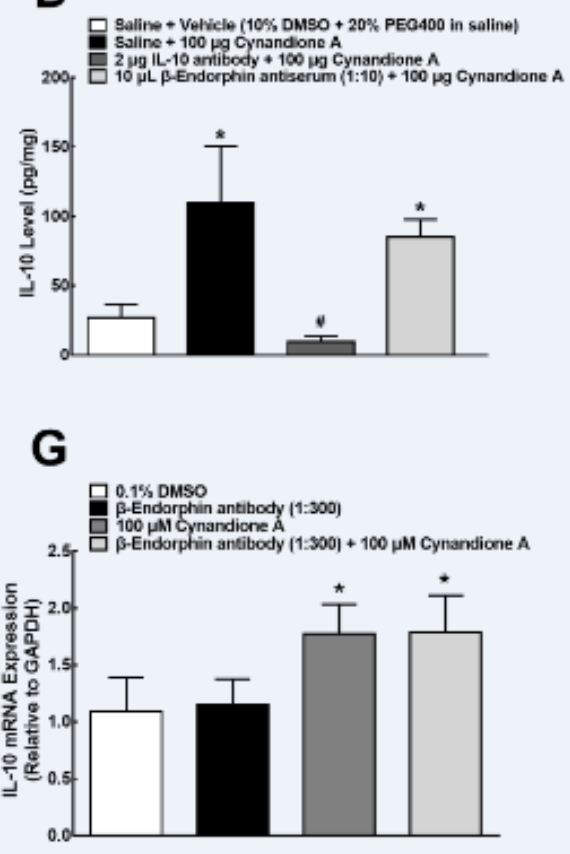
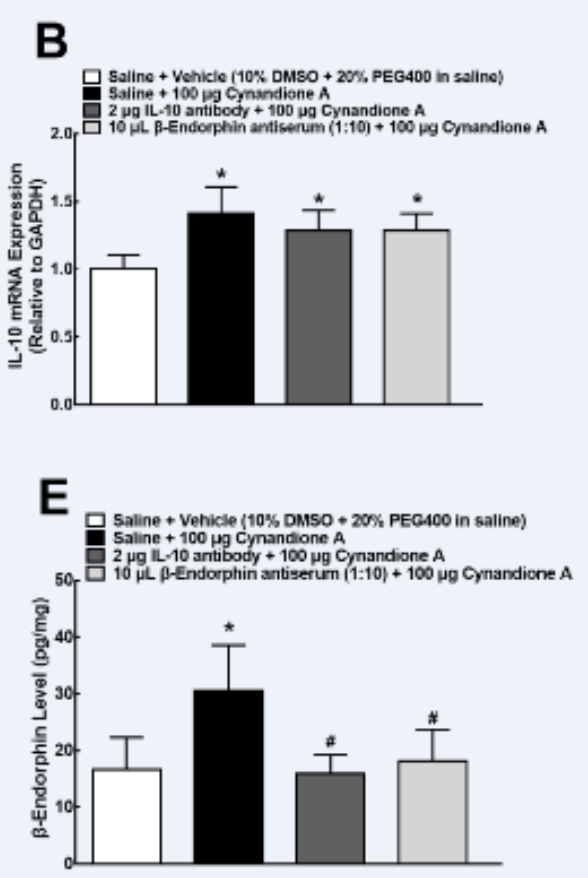
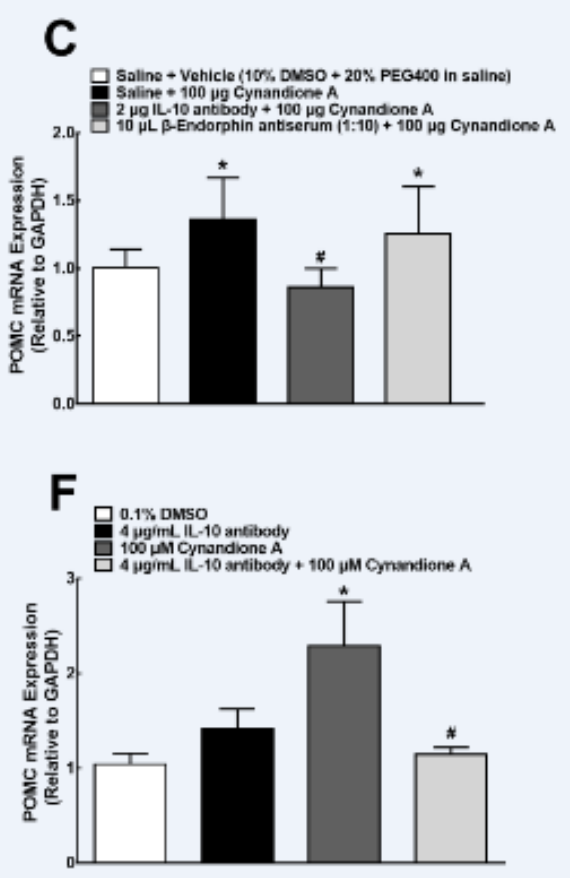

\section{Figure 6}

Blockade effects of the IL-10 antibody and $\beta$-endorphin antiserum on cynandione A-induced spinal mechanical antiallodynia (A), spinal gene expression of IL-10 (B) and the $\beta$-endorphin precursor proopiomelanocortin (POMC, C), and spinal protein expression of IL-10 (D) and $\beta$-endorphin (E) in neuropathic rats induced by L5/L6 spinal nerve ligation. Neuropathic rats received intrathecal injection of saline, the IL-10 antibody or $\beta$-endorphin antiserum followed by intrathecal injection of the vehicle or cynandione A 30 minutes later. The spinal cords were obtained immediately after the completion of behavioral test ( 1 hour after the last injection) for the detection of IL-10 and $\beta$-endorphin by using qRTPCR and enzyme-linked immunosorbent fluorescent assays, respectively. Blockade effects of the IL-10 antibody and $\beta$-endorphin antiserum on cynandione A-stimulated gene expression of POMC (F) and IL-10 $(\mathrm{G})$ in cultured primary microglial cells originated from 1-day-old neonatal rats. Data are shown as means \pm SEM ( $n=6$ per group in neuropathic rats or $n=3$ per group with two independent repeats in cultured primary cells). *, \# p<0.05 compared with the control and cynandione A treatment groups, respectively, analyzed by one-way ANOVA followed by the post-hoc Student-Newman-Keuls test. 


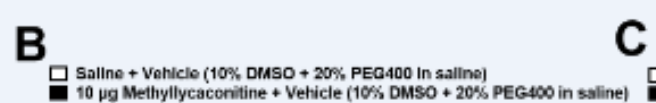

C

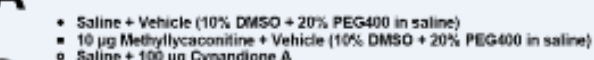

흐 60 . ㅁ.
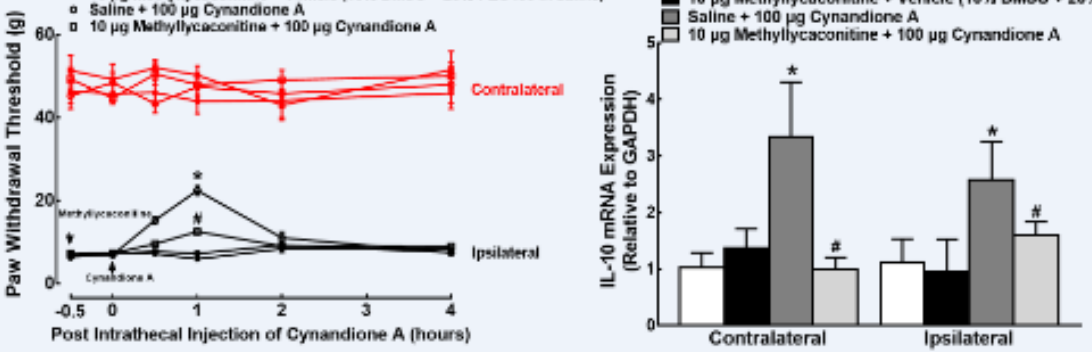

D

E
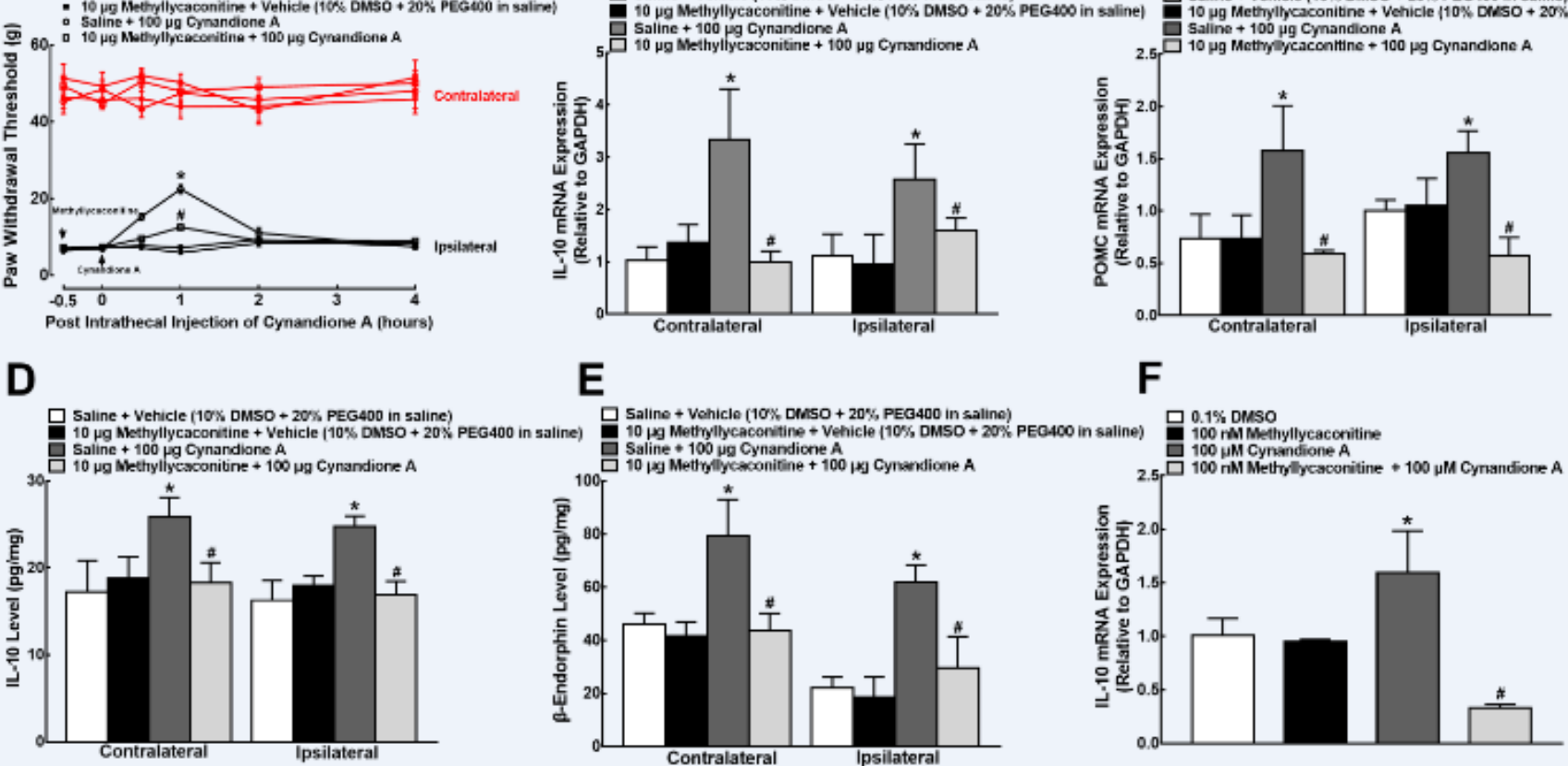

$\mathbf{F}$
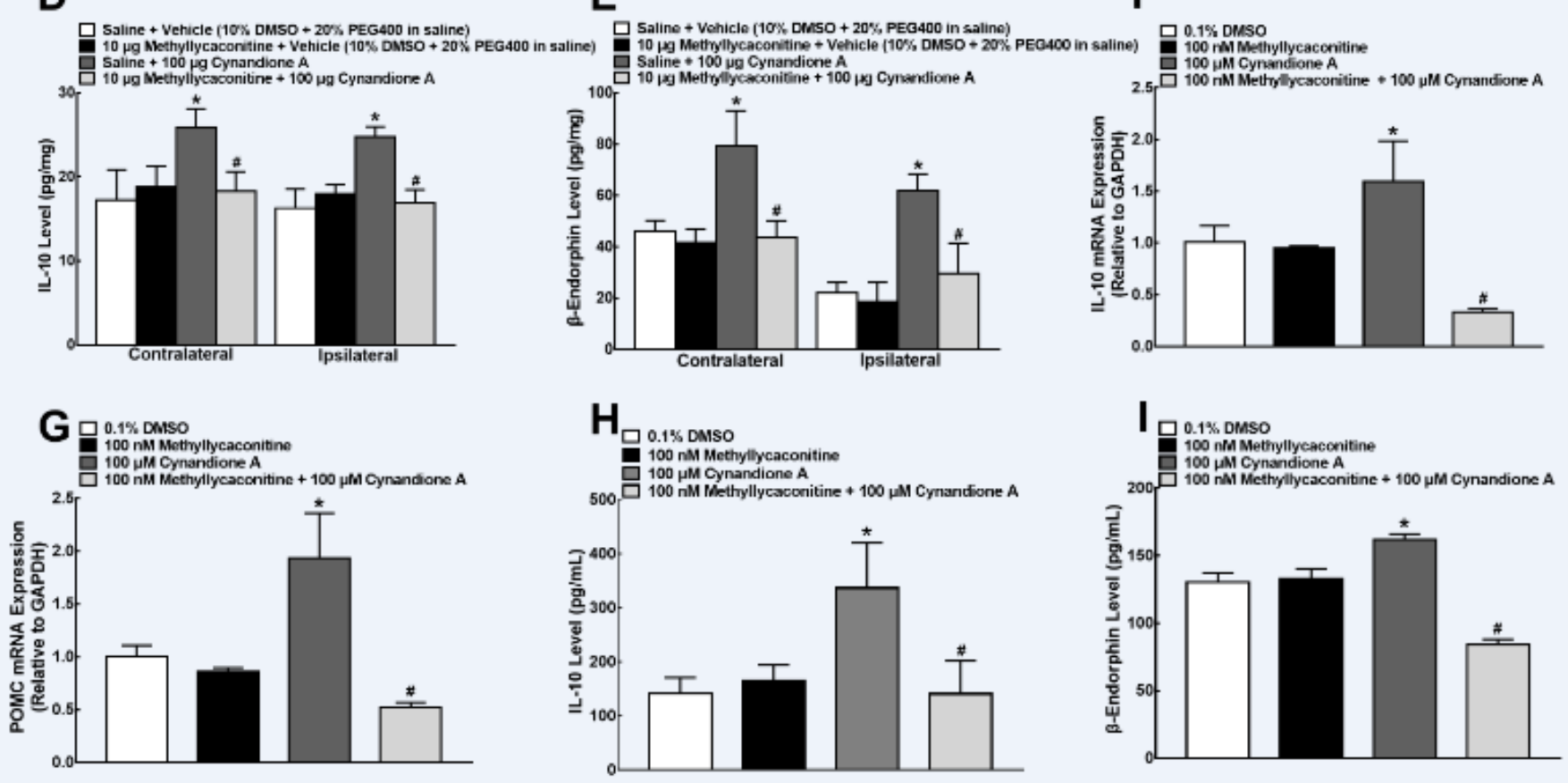

Figure 7

Blockade effects of the $\alpha 7$ nicotinic acetylcholine receptor ( $a 7 n A C h R)$ antagonist methyllycaconitine on cynandione A-induced spinal mechanical antiallodynia (A), spinal gene expression of IL-10 (B) and the $\beta$ endorphin precursor proopiomelanocortin (POMC, C), and spinal protein expression of IL-10 (D) and $\beta$ endorphin $(E)$ in neuropathic rats induced by spinal nerve ligation. Neuropathic rats received intrathecal the vehicle or methyllycaconitine 30 minutes followed by intrathecal saline or cynandione A. The spinal cords were obtained 1 hour after the last intrathecal injection for the detection of IL-10 and $\beta$-endorphin by using qRT-PCR and enzyme-linked immunosorbent fluorescent assays, respectively. Blockade effects of methyllycaconitine on cynandione A-stimulated gene $(F, G)$ and protein $(H, I)$ expression of IL-10 and $\beta$ endorphin in cultured primary microglial cells originated from 1-day-old neonatal rats. Data are shown as means \pm SEM ( $n=6$ per group in neuropathic rats or $n=3$ per group with two independent repeats in cultured primary cells). * $\# \mathrm{p}<0.05$ compared with the control and cynandione A treatment groups, respectively, analyzed by one-way or measures-repeated two-way ANOVA followed by the post-hoc Student-Newman-Keuls test. 


\section{A}
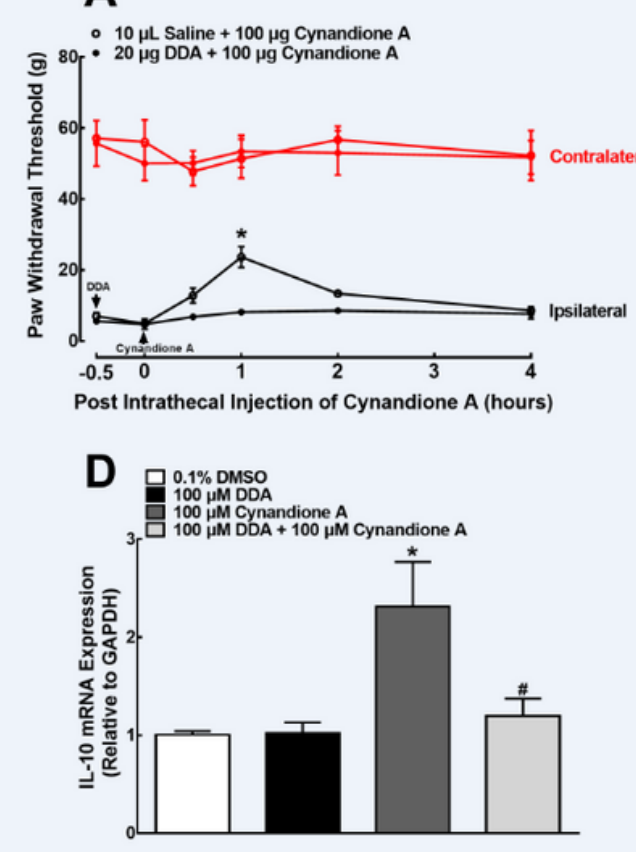

B
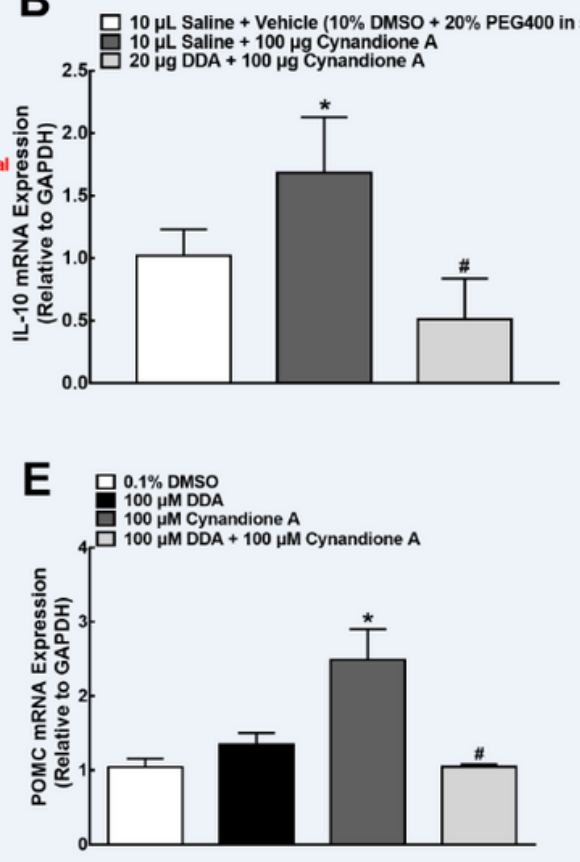

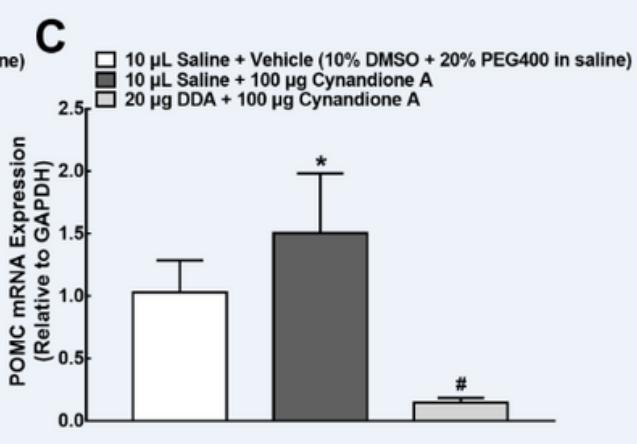

\section{Figure 8}

Blockade effects of the adenylyl cyclase inhibitor DDA on cynandione A-induced spinal mechanical antiallodynia (A) and mRNA expression of IL-10 (B) and the $\beta$-endorphin precursor proopiomelanocortin (POMC, $C$ ) in the spinal cords of neuropathic rats induced by spinal nerve ligation and cultured primary microglial cells originated from 1-day-old neonatal rats $(D, E)$. Neuropathic rats received intrathecal the vehicle or DDA 30 minutes followed by cynandione A. The spinal cords were obtained 1 hour after the last intrathecal injection for the detection of the IL-10 and POMC gene expression by using qRT-PCR. Data are shown as means \pm SEM ( $n=6$ per group in neuropathic rats or $n=3$ per group with two independent repeats in cultured primary cells). ${ }^{*}, \# p<0.05$ compared with the control and cynandione A treatment groups, respectively, analyzed by one-way or two-way ANOVA followed by the post-hoc Student-NewmanKeuls test. 

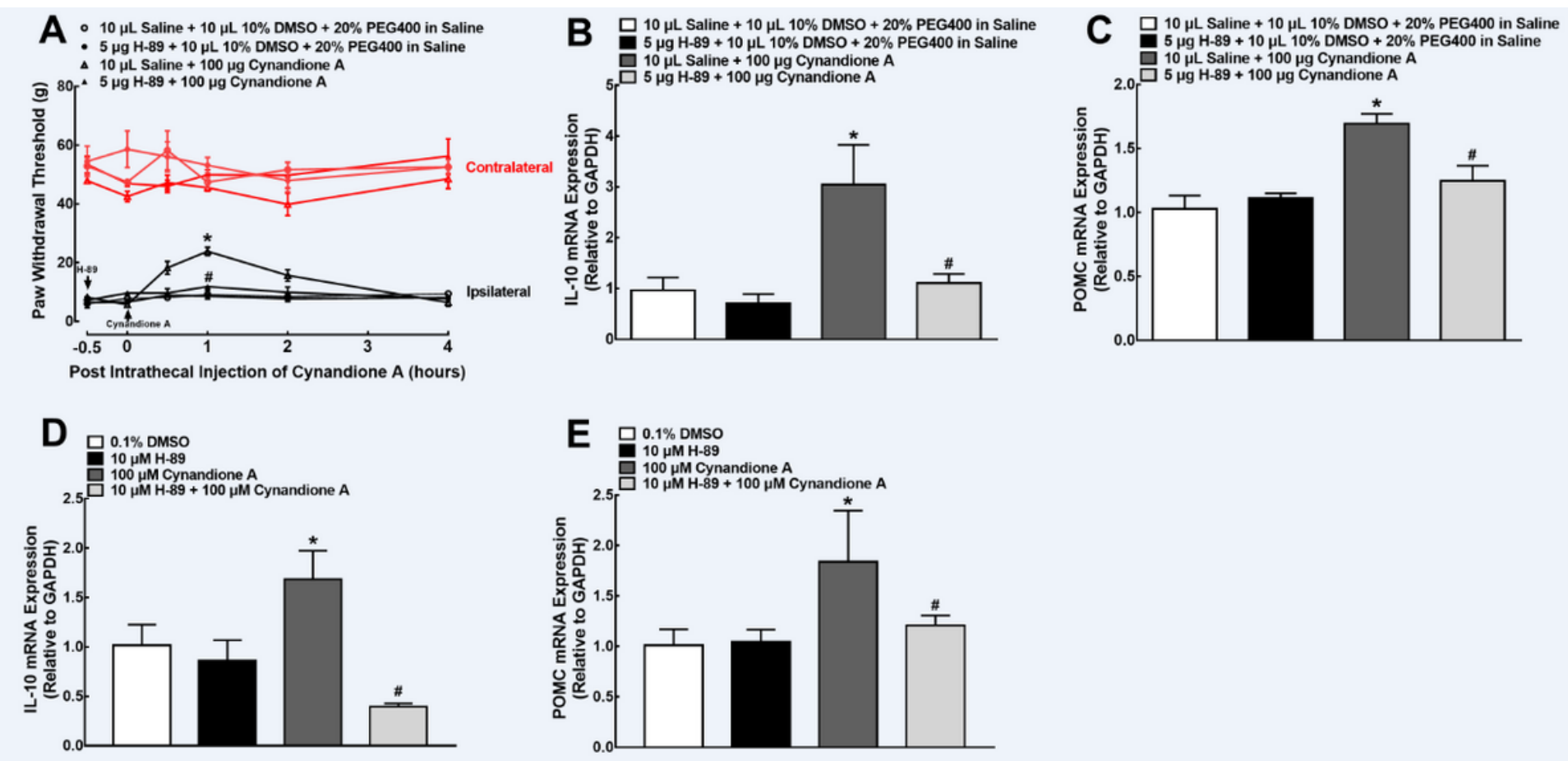

\section{Figure 9}

Blockade effects of the PKA activation inhibitor $\mathrm{H}-89$ on cynandione A-induced spinal mechanical antiallodynia (A) and mRNA expression of IL-10 (B) and the $\beta$-endorphin precursor proopiomelanocortin (POMC, C) in the spinal cords of neuropathic rats induced by L5/L6 spinal nerve ligation and cultured primary microglial cells originated from 1-day-old neonatal rats $(D, E)$. Neuropathic rats received intrathecal the vehicle or $\mathrm{H}-8930$ minutes followed by cynandione $\mathrm{A}$. The spinal cords were obtained 1 hour after the last intrathecal injection for the detection of the IL-10 and POMC gene expression using qRT-PCR. Data are shown as means \pm SEM ( $n=6$ per group in neuropathic rats or $n=3$ per group with two independent repeats in cultured primary cells). ${ }^{*}, \# p<0.05$ compared with the control and cynandione $A$ treatment groups, respectively, analyzed by one-way or measures-repeated two-way ANOVA followed by the post-hoc Student-Newman-Keuls test. 

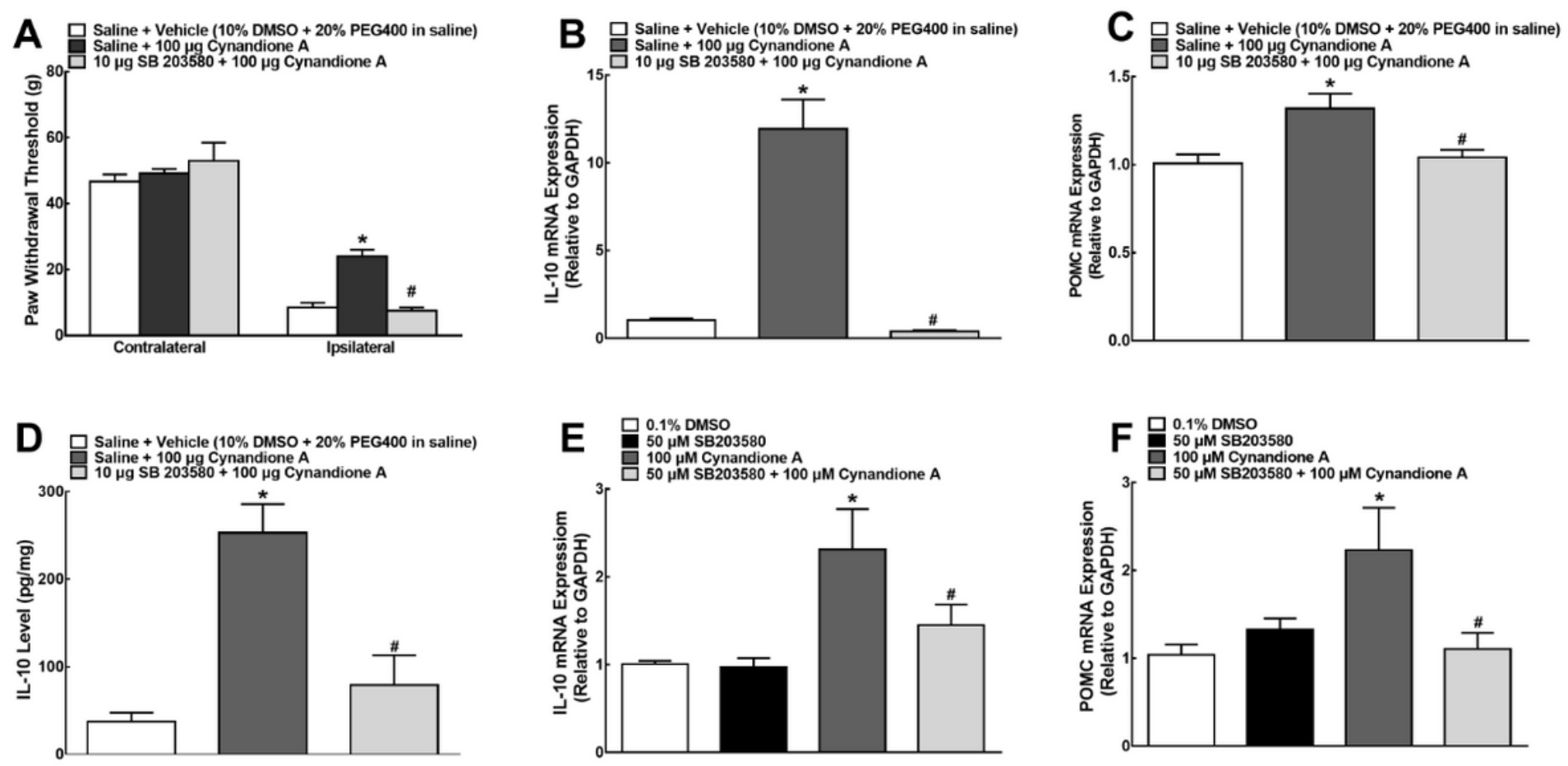

Figure 10

Blockade effects of the p38 activation inhibitor SB203580 on cynandione A-induced spinal mechanical antiallodynia (A) and mRNA expression of IL-10 (B) and the $\beta$-endorphin precursor proopiomelanocortin (POMC, C), and protein expression of IL-10 (D) in the spinal cords of neuropathic rats induced by L5/L6 spinal nerve ligation and cultured primary microglial cells originated from 1-day-old neonatal rats $(E, F)$. Neuropathic rats received intrathecal the vehicle or SB203580 30 minutes followed by intrathecal cynandione $A$ injection. The spinal cords were obtained 1 hour after the last intrathecal injection for the detection of the IL-10 and $\beta$-endorphin expression using qRT-PCR and enzyme-linked immunosorbent assays, respectively. Data are shown as means \pm SEM ( $n=6$ per group in neuropathic rats or $n=3$ per group with two independent repeats in cultured primary cells). ${ }^{*}, \# p<0.05$ compared with the control and cynandione A treatment groups, respectively, analyzed by one-way ANOVA followed by the post-hoc Student-Newman-Keuls test. 

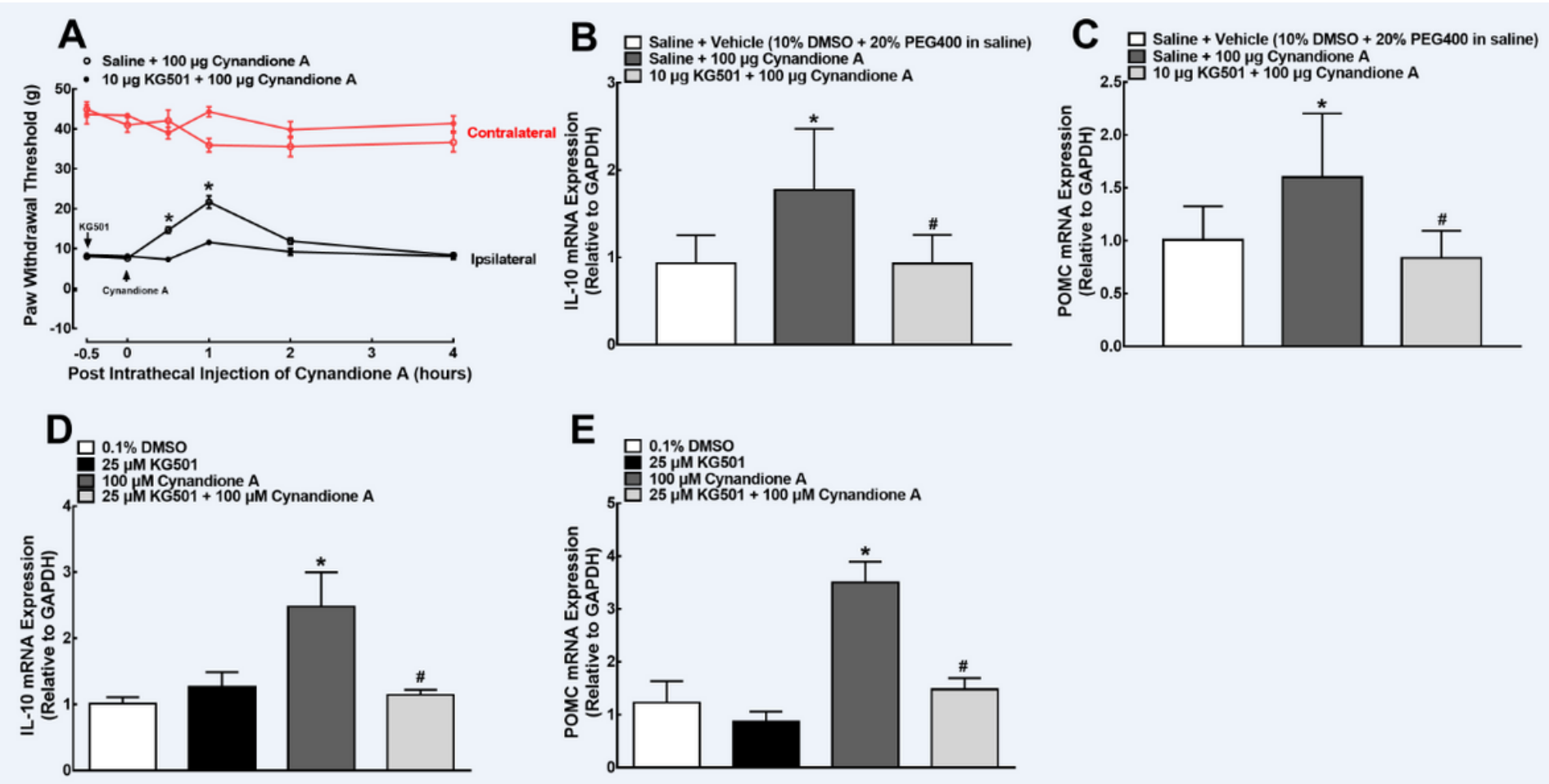

\section{Figure 11}

Blockade effects of the CREB activation inhibitor KG501 on cynandione A-induced spinal mechanical antiallodynia (A) and mRNA expression of IL-10 (B) and the $\beta$-endorphin precursor proopiomelanocortin (POMC, $C$ ) in the spinal cords of neuropathic rats induced by $L 5 / L 6$ spinal nerve ligation and cultured primary microglial cells originated from 1-day-old neonatal rats $(D, E)$. Neuropathic rats received intrathecal the vehicle or KG501 30 minutes followed by intrathecal cynandione A. The spinal cords were obtained 1 hour after the last intrathecal injection for the detection of IL-10 and POMC by using qRT-PCR. Data are shown as means \pm SEM ( $n=6$ per group in neuropathic rats or $n=3$ per group with two independent repeats in cultured primary cells). ${ }^{*}, \# p<0.05$ compared with the control and cynandione $A$ treatment groups, respectively, analyzed by one-way or measures-repeated two-way ANOVA followed by the post-hoc Student-Newman-Keuls test. 


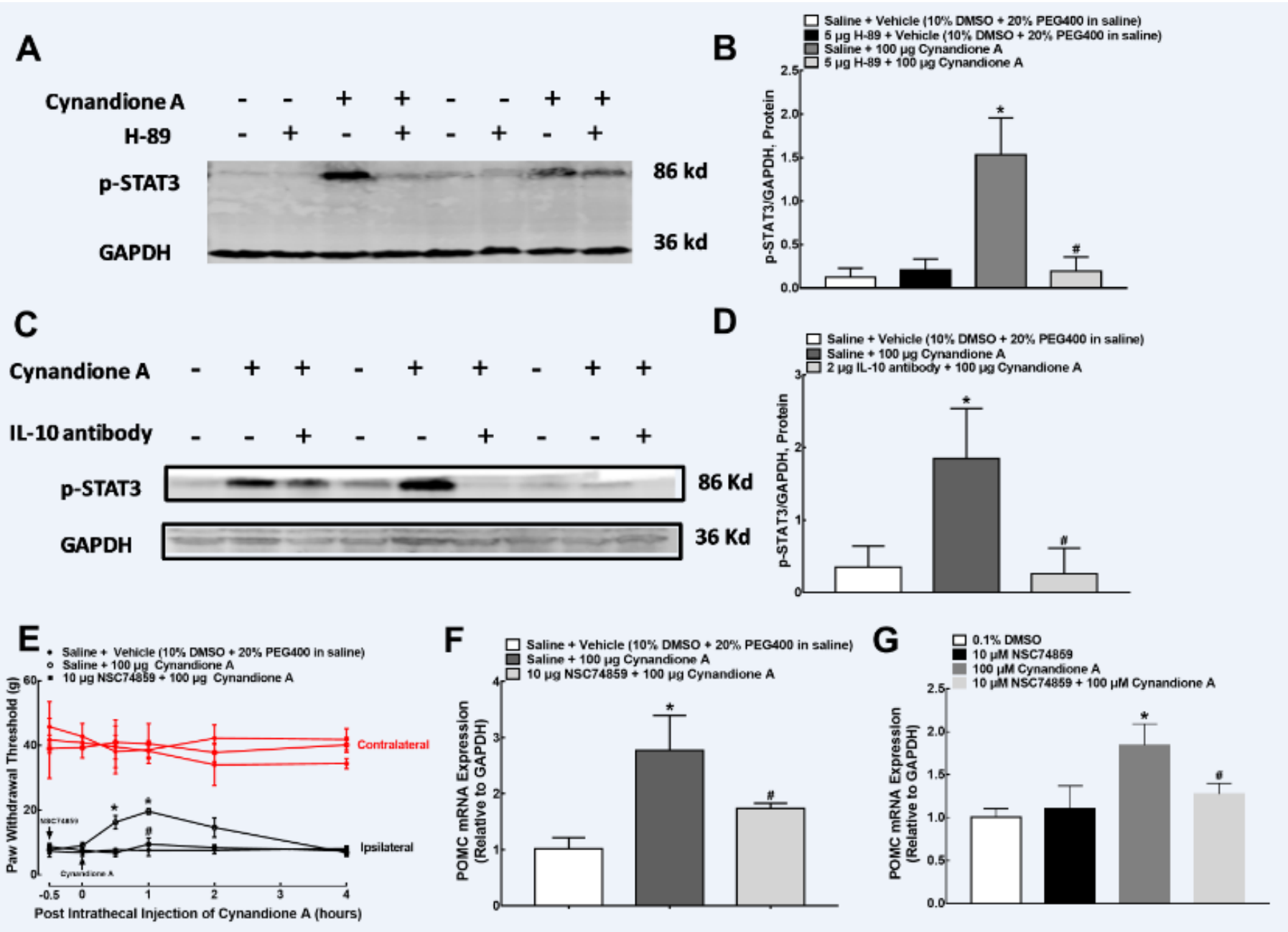

Figure 12

Blockade effects of the PKA activation inhibitor H-89 (A, B) and IL-10 antibody (C, D) on cynandione Astimulated spinal STAT3 phosphorylation in neuropathic rats induced by L5/L6 spinal nerve ligation. Blockade effects of the STAT3 activation inhibitor NSC74859 on cynandione A-induced spinal mechanical antiallodynia (E) and gene expression of the $\beta$-endorphin precursor proopiomelanocortin (POMC) in the spinal cords of neuropathic rats $(F)$ and cultured primary microglial cells originated from 1day-old neonatal rats $(\mathrm{G})$. Neuropathic rats received intrathecal H-89, the IL-10 antibody or NSC74859 30 minutes later followed by intrathecal cynandione A. The spinal cords were obtained 1 hour after the last intrathecal injection for the detection of STAT3 phosphorylation and POMC expression by using western blot and qRT-PCR, respectively. Data are shown as means \pm SEM $(n=6$ per group in neuropathic rats or $\mathrm{n}=3$ per group with two independent repeats in cultured primary cells). ${ }^{*}, \# \mathrm{p}<0.05$ compared with the control and cynandione A treatment groups, respectively, analyzed by one-way or measures-repeated twoway ANOVA followed by the post-hoc Student-Newman-Keuls test. 

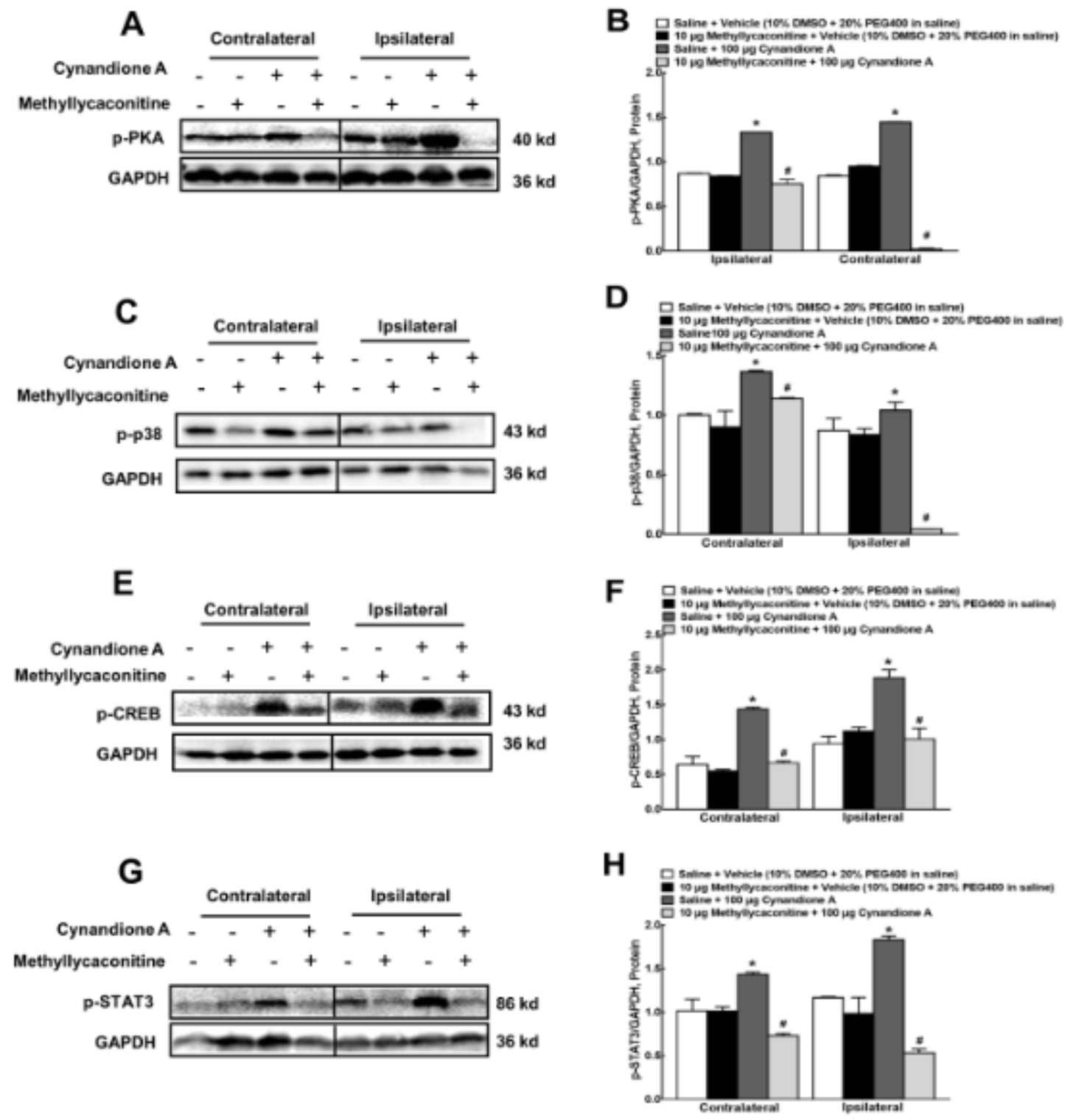

\section{Figure 13}

Blockade effects of the a7 nicotinic acetylcholine receptor ( $\mathrm{a} 7 \mathrm{nAChR})$ antagonist methyllycaconitine on cynandione A-induced phosphorylation of spinal PKA (A, B), p38 (C, D), CREB (E, F) and STAT3 $(G, H)$ in neuropathic rats induced by L5/L6 spinal nerve ligation. Neuropathic rats received intrathecal injection of the vehicle or methyllycaconitine 30 minutes later followed by intrathecal cynandione A. The spinal cords were obtained 1 hour after the last intrathecal injection for the phosphorylation detection by using western blot. Data are shown as means \pm SEM ( $n=6$ per group). * $\# p<0.05$ compared with the control and cynandione A treatment groups, respectively, analyzed by one-way ANOVA followed by the post-hoc Student-Newman-Keuls test. 


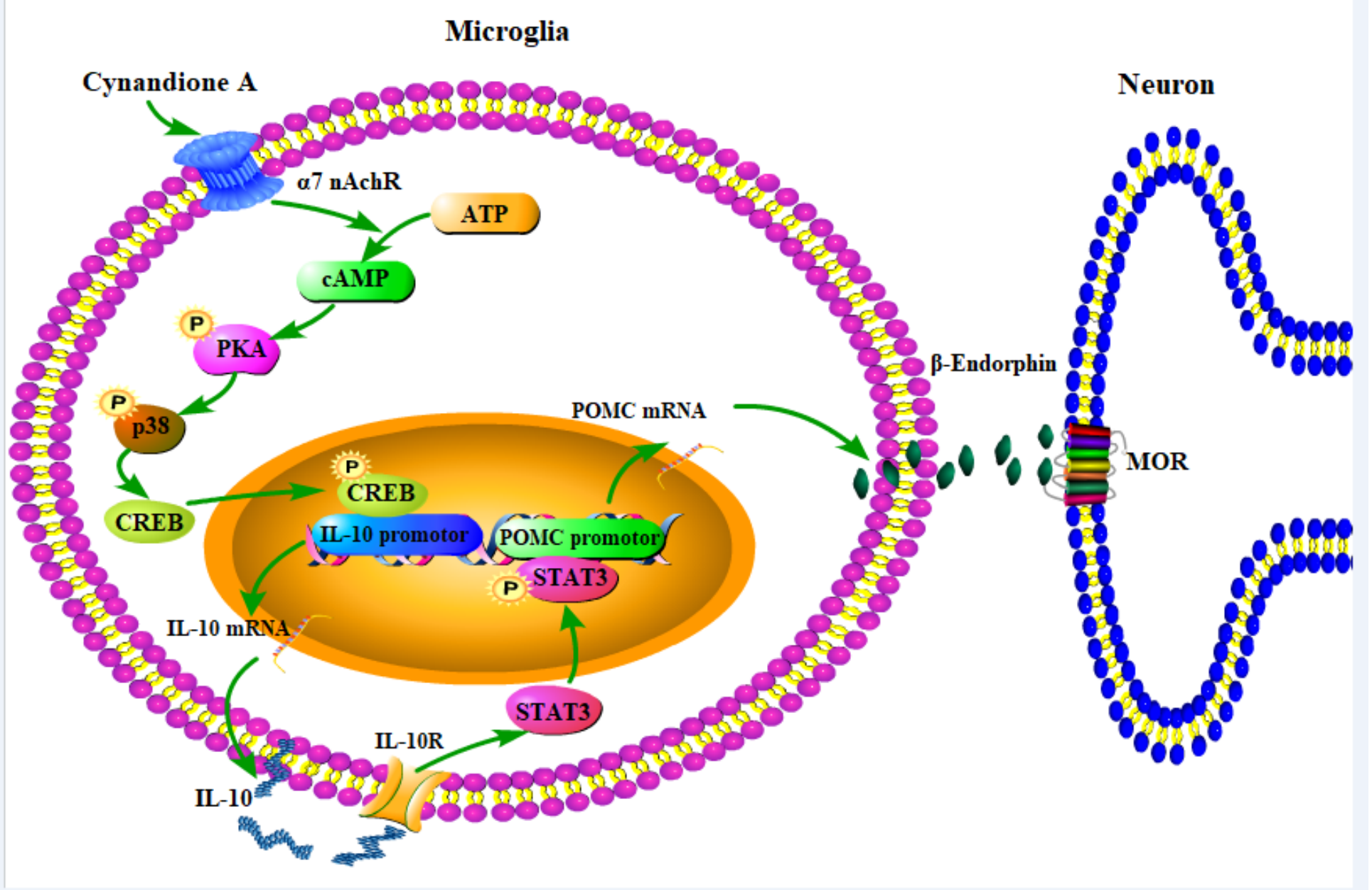

Figure 14

Illustration of the proposed mechanisms underlying the antinociceptive effects of cynandione A. Cynandione $A$ acts on the $\mathrm{a} 7$ nicotinic acetylcholine receptor ( $\mathrm{a} 7 \mathrm{nAChR}$ ) localized on the cellular membrane of microglia, and stimulates the expression of IL-10 through the CAMP/PKA/CREB pathway. IL-10 then activates the IL-10 receptor (IL-10R) located on the microglia membrane in an autocrime manner, leading to the transcription factor STAT3 phosphorylation, which in return to stimulates the $\beta$ endorphin expression. Afterwards, the secreted $\beta$-endorphin passes the microglial-neuronal synapse to activate post-synaptic neuronal $\mu$-opioid receptors (MORs) and produces antinociception. 